Nancy Paola

Hernández Clavijo*

María del Pilar

Sánchez Muñoz ***

Universidad

de La Salle, Colombia

Recibido: 12 de febrero de 2013

Concepto de evaluación: 20 de abril de 2013

Aprobado: 7 de mayo de 2013

Artículo de investigación

*Economista. Estudiante de la Maestría en Administración Pública y Política Pública, Universidad Tecnológico de Monterrey, Ciudad de México, México, Correo electrónico: nhernandez77@unisalle.edu.co, A01500260@itesm.mx

**Economista. Magíster en economía, Docente investigadora, Facultad de Ciencias Económicas y

Sociales, Universidad de La Salle,

Bogotá, Colombia. Miembro

del Grupo de Investigación

Economía y Desarrollo Humano, Universidad de La Salle.

Bogotá, Colombia.

Correo electrónico:

mdsanchez@unisalle.edu.co

\section{Análisis de las condiciones de vida de los beneficiarios del Programa Centro AMAR de la localidad de San Cristóbal en Bogotá, Colombia ${ }^{1}$}

\section{RESUMEN}

En esta investigación se recolectó y sistematizó la información de las fichas Sirbe, historia sociofamiliar, terapia ocupacional, nutrición, y de la entrevista semiestructurada aplicada, para describir e interpretar, desde el enfoque de capacidades de Nussbaum, la realidad socioeconómica particular de la población beneficiaria entre 2007 y 2009 del programa Centro AMAR en la localidad de San Cristóbal. En este contexto se identificó la falta de continuidad y acompañamiento en los procesos de los niños, niñas y adolescentes, el desinterés de los cuidadores para cambiar sus hábitos de crianza y una leve mejoría en la calidad de vida de las familias. Esto representa un reto para la construcción e implementación de las políticas públicas encaminada a fomentar el capital humano, consolidar el entorno familiar y propiciar elementos que contribuyan al bienestar.

Palabras clave: política pública, trabajo infantil, calidad de vida, capacidades.

Clasificación JEL: I38, J13, I31, I39

\section{Analysis of life conditions of the beneficiaries of AMAR Center Program in San Cristóbal, Bogotá, Colombia}

\section{ABSTRACT}

In this research we collected and systematized the information contained in the Sirbe filling cards (Sirbe is the acronym in Spanish for Sistema de Información para el Registro de Beneficiarios which means Beneficiary Registration Information System), regarding socio-familial history, occupational therapy, nutrition and in the information obtained through the semi-structured inter-

1 Este artículo es resultado del trabajo realizado como aporte de las autoras a la investigación, Incidencia sobre las Condiciones de Calidad de Vida, Capital Social y Restitución de Derechos de la Infancia en los Niños, Niñas y Adolescentes -NNA- que Egresaron del Centro AMAR, San Cristóbal II en el periodo 2007-2009, realizada entre 2010 y 2011 y financiada por la Universidad de la Salle. Las autoras agradecen el apoyo del equipo investigador, en especial a los estudiantes Angelina Garnica Carrillo, por la sistematización de la información registrada en el Centro AMAR; José Luís Cifuentes Martínez y Diana del Pilar Guzmán Ardila, por el acompañamiento en las entrevistas semiestructuradas y la tabulación de los resultados. 
view that was applied. This was carried out in order to describe and interpret, from Nussbaum's capabilities approach, the particular socioeconomic reality of the AMAR Center recipient population in San Cristóbal, Bogotá, between 2007 and 2009. We identified the lack of continuity and accompaniment in the processes for children and teenagers, the lack of interest of caretakers in order to change their raising habits and a slight improvement in the quality of life of the families. This represents a challenge in designing and implementing public policies that lead to promote human capital, strengthen family environment and generate elements that contribute to wellbeing.

Keywords: public policy, child labor, quality of life, capabilities.

JEL Classification: I38, J13, I31, I39

\section{Análise das condições de vida dos beneficiários do Programa Centro AMAR da zona de San Cristóbal em Bogotá, Colombia}

\section{RESUMO}

Nesta pesquisa, coletou-se e sistematizou-se a informação das fichas Sirbe, história sociofamiliar, terapia ocupacional, nutrição, assim como da entrevista semiestruturada aplicável para descrever e interpretar, a partir do enfoque de capacidades de Nussbaum, a realidade socioeconômica particular da população beneficiária entre 2007 e 2009 do programa Centro AMAR na zona de San Cristóbal. Nesse contexto, identificou-se a falta de continuidade e acompanhamento nos processos das crianças e adolescentes, o desinteresse dos cuidadores para mudar seus hábitos de criação e uma leve melhoria na qualidade de vida das famílias. Isso representa um desafio para a construção e implementação das políticas públicas encaminhadas para a fomentação do capital humano, consolidação do ambiente familiar e propiciação de elementos que contribuam para o bem-estar.

Palavras-chave: política pública, trabalho infantil, qualidade de vida, capacidades. 


\section{INTRODUCCIÓN}

Las políticas públicas para la reducción del trabajo infantil tienen como estrategia fomentar el capital humano, consolidar el entorno familiar y propiciar elementos que permitan construir capital social, restituir los derechos y mejorar la calidad de vida de los habitantes. De esta forma, los diferentes niveles de gobierno (nacional, departamental y municipal) se articulan para el logro de estos objetivos.

En este artículo se presentan los resultados de investigación sobre la política pública para la disminución del trabajo infantil desarrollada en Bogotá entre 2007 y 2009, especialmente en lo que hace referencia al programa Centro AMAR (Atención al Menor en Alto Riesgo). Durante el periodo de aplicación de este programa, la administración distrital, a través de organizaciones no gubernamentales, destinó recursos encaminados al desarrollo integral de las familias y los niños, niñas y adolescentes (NNA) vulnerables al trabajo infantil. Aunque las acciones que se han llevado a cabo en torno a la reducción de esta problemática posibilitan que los NNA y sus familias fortalezcan las capacidades y alcancen el desarrollo humano, los avances no han sido significativos en el logro de los objetivos propuestos, en especial, en lo que hace referencia al mejoramiento de la calidad de vida.

Para el desarrollo de esta investigación se contó con la participación de investigadores y estudiantes de la Universidad de La Salle, junto con profesionales de Coinfa ${ }^{2}$, entidad encargada de la administración del Centro AMAR ubicado en la localidad de San Cristóbal. El grupo interdisciplinar desarrolló una metodología de trabajo a través de la cual repensó, reinterpretó y reconceptualizó las categorías de análisis en tres componentes: capital social, restitución de derechos y calidad de vida. Aquí se presentan los resultados sobre este último componente.

La ficha Sistema de Información para el Registro de Beneficiarios (Sirbe), los formatos de historia

2 Entidad creada sin ánimo de lucro, fundada el 1 de marzo de 1997, orientada al progreso de las comunidades vulnerables mediante programas y proyectos que respondan a sus necesidades. sociofamiliar y visita domiciliaria, y los registros de terapia ocupacional, salud y nutrición, junto con la entrevista semiestructurada, elaborada por el equipo de trabajo, son los instrumentos utilizados para este análisis de caso, en especial lo relacionado con la calidad de vida de las familias beneficiadas del programa Centro AMAR.

Entre 2007 y 2009, 233 NNA fueron beneficiarios del servicio ofrecido, de los cuales 93 finalizaron el proceso ${ }^{3}$ en el Centro. En el año 2011, se pudo ubicar y entrevistar a 56, pertenecientes a 31 familias. En este documento se describen e interpretan los contextos ex ante (condición inicial) y ex post (condiciones finales) de estas 31 familias.

Esta investigación sirve como herramienta de análisis para el seguimiento de políticas públicas encaminadas a la reducción del trabajo infantil. Para tales efectos, inicialmente se presenta el marco teórico en el que se basó la investigación. Luego se presenta el contexto en el que la política de mitigación del trabajo infantil se desarrolla, teniendo en cuenta tanto la política nacional como local. En la tercera parte de este documento se describe la metodología utilizada. Por último, se presentan los resultados obtenidos en términos de calidad de vida de las familias objeto de estudio, al igual que las conclusiones y recomendaciones.

\section{CAPACIDADES Y CALIDAD DE VIDA}

Para analizar la calidad de vida de un grupo poblacional, en los últimos años se han utilizado indicadores como el índice de condiciones de vida (ICV) y el índice de desarrollo humano (IDH). El primero, de acuerdo con Sarmiento y Ramírez como se citó en Delgado (2001), busca combinar en una sola medida: 1) variables de potencial de acceso a bienes físicos; 2 ) variables que miden el capital humano de las personas que conforman un hogar; 3 ) acceso a los servicios públicos; 4) acceso de niños y jóvenes

3 Son los NNA que permanecieron siete meses o más en el Centro AMAR, y se les brindó garantías y acompañamiento individual y familiar para disminuir la vulnerabilidad al trabajo infantil y, de esta forma, mejorar sus condiciones de vida. 
a servicios escolares; 5) características del jefe del hogar que posibilitan su acceso al mercado de trabajo, entre las más importantes. Por otro lado, el ICV es un indicador multivariado que no cuenta con el ingreso como variable explicativa, ya que supone que las demás variables que se encuentran en él lo sustituyen.

En 1990, el Programa de las Naciones Unidas para el Desarrollo (PNUD) propuso el índice de desarrollo humano (IDH); este agrega diferentes factores esenciales de la vida humana como la longevidad, los conocimientos, la participación política, el acceso al trabajo, entre otros, es un intento por elaborar un concepto más cualitativo acerca de la calidad de vida (Delgado, 2001).

Por su parte, autores como Martha Nussbaum y Amartya Sen conciben la calidad de vida de una persona en función de sus capacidades. En palabras de los autores "la calidad de vida de una persona debe valorarse en términos de sus capacidades. Una capacidad es la habilidad o potencial para hacer o ser algo, más técnicamente, para lograr un cierto funcionamiento" (1996, p. 88).

En este sentido,

Sen sostiene que la vida puede concebirse como un conjunto de funcionamientos o logros, esto es un conjunto de estados y acciones, donde la realización de una persona puede entenderse como el vector de sus funcionamientos, abarcando estos cosas tales como por ejemplo "estar bien alimentado", "tener buena salud", o "participar en la vida de la comunidad" [...]. Por su parte, la idea de capacidad representa las diversas combinaciones de funcionamientos que puede realizar una persona, y de ahí que la capacidad de una persona refleje su libertad para llevar adelante un tipo de vida u otro (Pereira, 2006, p. 39).

Es decir, las libertades individuales se encuentran representadas en la capacidad que tienen las personas para obtener combinaciones de sus logros. En palabras de Sen: se debe prestar especial atención a la expansión de las capacidades de las personas para llevar el tipo de vida que valoran y que tienen razones para valorar [...]. EI éxito de una sociedad ha de evaluarse, desde este punto de vista, principalmente en función de las libertades fundamentales de que disfrutan sus miembros (2000, pp. 34-35).

Para Nussbaum (2007), los seres humanos presentan muchas necesidades, pero también disponen de las siguientes capacidades que son esenciales para una vida digna:

1. Vida: Toda persona debería ser capaz de llevar una vida de una duración normal.

2. Salud física: Tener adecuadas condiciones de salud, alimentación y vivienda.

3. Integridad física: Gozar de libertad de movimientos y seguridad.

4. Sentidos, imaginación y pensamiento: Recibir una educación que permita desarrollar estas capacidades y un ambiente de libertad para manifestar gustos y creencias.

5. Emociones: Capacidad de amar, de estar agradecido en las diversas formas de asociación humana.

6. Razón práctica: Ser capaz de formular una concepción del bien y un plan de vida.

7. Afiliación: Capacidad de vivir con otros, de establecer relaciones sociales, de ser respetado y no discriminado.

8. Otras especies: Ser capaz de respetar a los animales, las plantas y demás especies del mundo natural.

9. Juego: Ser capaz de jugar, reír y disfrutar de actividades recreativas.

10. Control sobre el propio ambiente: Gozar de oportunidades de participación políti$\mathrm{ca}$, derechos de propiedad y del trabajo (pp. 88-89). 
De estas diez capacidades, el equipo de trabajo reconceptualizó siete que son: afiliación, salud física, sentidos, imaginación y pensamiento, control sobre el propio entorno, integridad física, razón práctica y juego, considerando que son las más relevantes para el análisis. Estas capacidades se agruparon en cinco categorías: familia y redes sociales, salud y nutrición, educación, integridad física y recreación y tiempo libre.

\section{CALIDAD DE VIDA Y POLÍTICA PÚBLICA PARA LA REDUCCIÓN DEL TRABAJO INFANTIL}

Se puede afirmar que el trabajo infantil limita desde diferentes perspectivas la imaginación, emociones, salud física y mental de los NNA, entre otras. Asimismo, este es un fenómeno que impide que ellos satisfagan algunas necesidades clave para su desarrollo, como la recreación y la educación, con lo cual se aumenta las brechas de pobreza en los territorios.

El trabajo infantil deteriora el desarrollo físico, mental y emocional de la persona, además que vulnera sus derechos fundamentales. Por lo general, cuando un NNA tiene que trabajar, se le dificultan sus procesos de socialización y de formación integral en la escuela, lo que se traduce en la pérdida de capital humano.

La pobreza y el desplazamiento son factores que generan trabajo infantil, pero los hábitos y creencias de adultos toman gran importancia, porque:

el valor que se le asigna al trabajo en el proceso de formación y autodisciplina, la transmisión generacional de oficios o el temor al ocio, son algunos ejemplos de las justificaciones culturales dadas al trabajo de los niños, niñas y adolescentes. (Alcaldía Mayor de Bogotá, 2004a, pp. 17-18).

Según la Consultoría para los Derechos Humanos y el desplazamiento - Codhes - (2009) se calcula que entre 1985 y el 2007 fueron desplazados 4.075.580 personas, de las cuales un 35\% estaban en Bogotá. Una de las características de estas familias es que son numerosas y llegan a la ciudad sin recursos económicos, esto las obliga a vivir en situaciones de indigencia que, de cierta manera, las conlleva a exponer a sus hijos al trabajo en calle $y$, por consiguiente, a la desescolarización y otras circunstancias que afectan el desarrollo de una vida digna y el goce de sus derechos.

El trabajo infantil, igualmente, está relacionado con aspectos estructurales como el desempleo y la falta de ingresos socioeconómicos en las familias, lo que se convierte en un factor de riesgo de explotación laboral para los NNA. Por otra parte, hay otras causas que se asocian a esta problemática como la violencia y el maltrato, la falta de espacios adecuados para el ocio y la recreación, junto a la baja calidad de la educación. Como lo plantea la Alcaldía Mayor de Bogotá (2004a, p. 18), "la baja calidad de esta, su rigidez y la no pertinencia de los currículos [suelen] expulsar tempranamente a los niños, niñas y adolescentes hacia el mundo del trabajo", lo que significaría que en el largo plazo el trabajo infantil podría constituirse en un obstáculo a la formación de capital humano y en la participación del niño y la niña en el mundo laboral.

Una de las situaciones relacionadas con el trabajo infantil se encuentra articulada a la alta recurrencia de los NNA explotados laboralmente provenientes de madres menores de edad (entre los 12 y 15 años). Ellas, en la mayoría de las ocasiones, se ven obligadas a estar en el mercado laboral informal, a fin de sustentar los gastos que implican responder por sus hijos; lo cual las obliga a desertar del ámbito escolar y, por lo general, obstruir la terminación del nivel básico de primaria

Como lo afirma González en el Informe de desarrollo humano: Bogotá una apuesta por Colombia, "la ampliación de las capacidades se logra mediante políticas que contribuyan a mejorar el ingreso, crear empleo, disminuir la desigualdad y acceder a los servicios sociales básicos, como educación, salud y seguridad alimentaria" (2008, p. 38). En concordancia con lo anterior, los diferentes niveles de gobierno, junto con los actores civiles, 
se han preocupado por reducir el número de NNA que trabajan. Igualmente, la academia ha jugado un papel fundamental en la construcción y seguimiento de la política pública encaminada al logro de este objetivo. En el año 2004, la Alcaldía Distrital de Bogotá, en cooperación con la Organización Internacional del Trabajo (OIT), realizó un estudio para conocer la situación de los NNA en riesgo de ser víctimas de las peores formas de trabajo infantil en cinco localidades de la ciudad. Se identificó que:

1540 niños y niñas víctimas de explotación en las peores formas de trabajo infantil, principalmente en comercio callejero, comercio en plazas de mercado y reciclaje, $y$ en menor número en minería artesanal, servicio doméstico y limpiavidrios callejeros de vehículos. El mayor número se encontró en la localidad de Kennedy, dentro de la plaza de mercado Corabastos, donde se hallaron 206 niñas y 241 niños (2004b, p. 13).

Además, este estudio encontró que más de dos tercios de los NNA no están estudiando y las razones principales para justificar la inasistencia escolar, según los responsables, son la insuficiencia de cupos en las escuelas públicas, seguido de la falta de dinero de los padres y el argumento que los niños y niñas no tienen edad suficiente para estudiar (Alcaldía Mayor de Bogotá, 2004b).

De otro lado, la mayor parte de las familias tiene ingresos menores al salario mínimo, viven en cuartos alquilados y en inquilinatos situados en los barrios pobres en los alrededores de la central de abastos, en condiciones precarias de servicios habitacionales y en hacinamiento. La escolaridad de los padres y madres de familia es en promedio baja, con presencia de analfabetismo de hasta el $10 \%$, mayor entre los hombres. Esto implica graves consecuencias para el desarrollo físico, mental y social de los niños y las niñas, lo cual reduce sus oportunidades futuras de progreso individual y cultural y de su desempeño como personas (Alcaldía Mayor de Bogotá, 2004b).
En este sentido, el estudio, realizado por Quiroga,

...evalúa empíricamente el comportamiento de las familias beneficiarias del Programa Familias en Acción, frente a la decisión de enviar a sus hijos a estudiar o a trabajar y como resultado encontró que el Programa tiene un efecto positivo, aunque pequeño, sobre los niños que permanecían inactivos (no estudian ni trabajan) y aumenta la tasa de asistencia de los niños trabajadores, a la vez que reduce la probabilidad de que las familias beneficiarias, ante crisis o eventos adversos, decidan enviar a sus hijos al mercado laboral (2006, p. 15).

De acuerdo con cifras del DANE (2007), 46.523 niños y niñas de los estratos 1 y 2 en Bogotá fueron obligados a incorporarse a actividades laborales en condiciones de informalidad, maltrato, soledad y explotación. La tasa de ocupación de NNA trabajadores de los estratos 1 y 2 fue de $9,6 \%$, lo cual equivale a que 1 de cada 10 NNA trabajó, el 53\% de dicha población realizó actividades de comercio informal y el $21 \%$ se desempeñó en el área de servicios, la mayoría de estos NNA (46\%) no percibieron ingresos y otros ganaban poco menos de la cuarta parte de un salario mínimo.

Durante el 2007 se identificaron 853 menores trabajadores, de los cuales 261 se encuentran entre las edades de 5 a 11 años de edad. Las principales actividades a las que se dedican los y las niñas trabajadores informales son: ventas ambulantes, en comercio al por menor y en hogares privados con servicio doméstico (Alcaldía Mayor de Bogotá, 2009, p. 8).

En el Plan de Desarrollo Nacional, Estado Comunitario: Desarrollo para Todos 2006-2010, la meta era reducir la participación laboral de los NNA entre 10 y 17 años de edad al 5\% en 2010 y 
al 2,5\% en 2019. Para contribuir a ello, se formuló y puso en marcha la Estrategia Nacional para la Prevención y Erradicación de las Peores Formas de Trabajo Infantil (PFTI) 2008-2015 (Ministerio de Protección Social, 2008). El objetivo de esta estrategia era aumentar la escolaridad y consolidar a la familia como eje central de progreso.

Por otra parte, en el año 2006 se proclamó la Ley 1098, Infancia y Adolescencia. En ella, se previó que los NNA serán protegidos contra la explotación económica por parte de sus padres, representantes legales, quienes vivan con ellos, o cualquier otra persona, de la mendicidad y de la situación de vida en calle. En su artículo 35 se establece que la edad mínima de admisión al trabajo y derecho a la protección laboral de los adolescentes autorizados para trabajar será entre los 15 y 17 años, con la autorización expedida por un inspector de trabajo, con el propósito de que gocen de las protecciones laborales consagradas en el régimen laboral colombiano.

A nivel municipal, para el caso de Bogotá, la Secretaría de Integración Social y, específicamente, la Subdirección para la Infancia, en busca de reducir el trabajo infantil ha promovido proyectos enmarcados en los planes de desarrollo, tales como el de Infancia y Adolescencia Feliz y Protegida Integralmente. Dentro de este proyecto se han implementado programas enfocados a la protección de los NNA, en especial aquellos que se encuentran en situación irregular o alto riesgo, con la creación de los centros AMAR, cuya filosofía es "propugnar porque estos sean atendidos integralmente con sus familias, para evitar la institucionalización y en general darles una atención personalizada que supla todas sus necesidades" (Alcaldía Mayor de Bogotá, 1999).

En el año 2011 estaban en servicio once centros AMAR, los cuales se encontraban ubicados en diferentes localidades de la capital. Los centros AMAR son la instancia encargada de desarrollar procesos (durante un año) encaminados a la protección, la garantía y el restablecimiento de los derechos de los NNA en edades de 5 a 17 años (población beneficiaria), que estén vivenciando situaciones de vulnerabilidad como: trabajo infantil, encierro parentalizado y acompañamiento laboral, con el objetivo de mejorar su calidad de vida y dar las bases para la generación de capital social (Moreno, 2009).

De acuerdo con la Fundación Centro de Investigación y Promoción Comunitaria (Ciproc):

los Centros Amar, son instituciones adscritas a la Secretaria Distrital de Integración que desarrollan acciones de prevención y erradicación de la explotación infantil, tienen como objetivo final, prevenir que niño/as y jóvenes se vinculen tempranamente a actividades laborales, buscando protegerlos, creando y fortaleciendo escenarios de socialización que promuevan, y garanticen los derechos de niño/ as, y jóvenes; que les permitan vivir plenamente su niñez a través de acciones intencionales, desde modelos pedagógicos que propicien su desarrollo integral y armónico (2009).

Para esta investigación, el estudio se realizó en el Centro AMAR San Cristóbal II (administrado por Coinfa). En términos de cobertura, desde allí, se atiende un promedio de 80 NNA al año, lo cual corresponde aproximadamente a 47 familias que se benefician de los servicios integrales que brinda la organización, en los niveles tanto de intervención psicosocial, individual y familiar como de productividad.

\section{METODOLOGÍA}

El proceso de investigación fue interdisciplinario, en él participaron economistas y trabajadores sociales, junto con profesionales de Coinfa, para describir e interpretar las condiciones de los NNA que egresaron del Centro AMAR San Cristóbal II entre los años 2007 y 2009. Esto se realizó con base en tres componentes: capital social, restitución de derechos y calidad de vida. Se estableció que un NNA terminaba el proceso si permanecía en el Centro siete o más meses. 
En particular, para el componente de calidad de vida, se tuvieron en cuenta siete de las diez capacidades descritas por Nussbaum, las cuales se agruparon en cinco categorías, como lo muestra la tabla 1.

Se implementó como técnica de investigación la revisión documental de las fichas Sirbe, los formatos de historia sociofamiliar y visita domiciliaria, y los registros de terapia ocupacional, salud y nutrición que son diligenciados por los profesionales encargados, con base en la información suministrada en el momento del ingreso del NNA beneficiarios del programa y del seguimiento producto de la intervención por parte de Centro AMAR. Esta información se depuró y sistematizó para poder realizar el respectivo análisis.

Una vez analizadas estas categorías (tabla 1) se llegó a la conclusión con el grupo de investigación que el instrumento más adecuado para abordar a las familias e indagar sobre sus condiciones socioeconómicas, después de haber recibido los beneficios del programa, era la entrevista semiestructurada (anexo A). Esto se debe a que este tipo de entrevistas se concibe como una técnica que brinda la posibilidad de acercarse al conocimiento de la subjetividad de los sujetos; es decir, el investigador captura las vivencias del entrevistado a través de la comunicación, con lo cual construye la propia biografía de ese interlocutor (Macoly \& Macoly como se citó en Carvajal, 2008).

La entrevista se realizó con los acudientes de los NNA y jóvenes que representaron la población sujeto de investigación y que fue posible contactar, dado que esta población en su mayoría vivían en arriendo y su lugar de residencia era cambiante, lo cual imposibilitó la vinculación de más familias para el estudio. Para la construcción del formato de la entrevista se tuvo en cuenta las categorías de análisis, como se observa en el anexo C. Por lo anterior, se construyeron indicadores con base en las capacidades humanas básicas planteadas por Martha Nussbaum (anexo B). Esto permitió dar un enfoque

Tabla 1.

\begin{tabular}{|c|c|c|c|}
\hline \multicolumn{4}{|c|}{ Categorías de análisis } \\
\hline Categoría & Capacidades & Variables, estados & Descripción \\
\hline \multirow{5}{*}{$\begin{array}{l}\text { Familia y redes } \\
\text { sociales }\end{array}$} & \multirow{4}{*}{$\begin{array}{l}\text { Control sobre el } \\
\text { propio entorno }\end{array}$} & Estrato & Estrato socioeconómico \\
\hline & & Ingresos familiares & Nivel de ingresos en el hogar \\
\hline & & $\begin{array}{l}\text { Tenencia de la } \\
\text { vivienda }\end{array}$ & Vivienda propia o en arriendo \\
\hline & & Servicios Públicos & $\begin{array}{c}\text { Acceso a los servicios de luz, alcantarillado y agua potable, } \\
\text { gas domiciliario, alumbrado público, entre otros }\end{array}$ \\
\hline & Razón práctica & Proyecto de vida & Aspiraciones de los NNA y familia \\
\hline \multirow{2}{*}{ Salud y nutrición } & \multirow{2}{*}{ Salud física } & Salud & $\begin{array}{c}\text { Afiliación a un régimen de salud, cuadro de vacunación, } \\
\text { enfermedades y tratamientos }\end{array}$ \\
\hline & & Nutrición & Alimentación y su calidad \\
\hline Educación & $\begin{array}{l}\text { Sentidos, } \\
\text { imaginación y } \\
\text { pensamiento }\end{array}$ & Escolaridad & $\begin{array}{l}\text { Proceso de aprendizaje, gusto por la institución, condiciones } \\
\text { como: elementos de apoyo, transporte, entre otros }\end{array}$ \\
\hline \multirow[t]{2}{*}{ Integridad física } & \multirow[t]{2}{*}{ Integridad física } & Factores de riesgo & $\begin{array}{l}\text { Maltrato físico, psicológico, abuso sexual, prostitución, } \\
\text { mendicidad, tendencias suicidas, drogadicción, maltrato, } \\
\text { y remisión a otras instituciones }\end{array}$ \\
\hline & & Trabajo Infantil & Condiciones en que se dio el trabajo infantil \\
\hline $\begin{array}{l}\text { Recreación } \\
\text { y tiempo libre }\end{array}$ & Juego & Recreación & Tiempo libre y actividades en familia \\
\hline
\end{tabular}

Fuente: Elaboración de las autoras con base en las capacidades de Nussbaum (2007). 
diferente a los métodos tradicionales basados en el IDH y el ICV, para analizar la información recolectada a través de la entrevista semiestructurada.

Previamente se contactó a la población por medio telefónico, búsqueda activa en sitios de trabajo, tales como la plaza de mercado del 20 de Julio y referencias dadas por las mismas personas entrevistadas. Para la implementación de las entrevistas se contó con el acompañamiento de dos profesionales (psicóloga y trabajadora social) del Centro AMAR.

En la recolección de la información se implementó como estrategia, con previa autorización de los(as) entrevistados(as), la grabación y transcripción de las narraciones hechas por ellos(as), para escuchar la relatoría de los entrevistados y poder hacer un análisis cualitativo exhaustivo. Así, la presentación de los hallazgos está fundamentada en los resultados, tanto del análisis realizado a partir de la información de las 21 entrevistas que contaron con transcripción, correspondientes a 42 NNA, como de los que dan cuenta de la situación en la que se encontraron los 56 NNA que constituyeron la muestra de la población sujeto de investigación.

\section{RESULTADOS}

En el Centro AMAR de la localidad de San Cristóbal II - Bogotá, en el año 2007 ingresaron 65 y egresaron 70 NNA, de los cuales solo 32 superaron el proceso. Para el año 2008, ingresaron 101, egresaron 79 y superaron el proceso 52 NNA. En el año 2009, ingresaron 18 NNA, egresaron 84 y 71 superaron proceso. Es decir, durante el periodo de estudio terminaron el proceso el $84 \%$ de los NNA que lo iniciaron, esto evidencia las dificultades de algunas familias para continuar recibiendo el apoyo del Estado, posiblemente por cambios de residencia y por los hábitos de crianza propios de los progenitores.

\section{Familia y redes sociales}

En esta categoría se incluye el análisis de aspectos como el estrato socioeconómico, los ingresos de la familia, el tipo de vivienda y el acceso a los ser- vicios públicos básicos. En la gráfica 1 se observa que las familias de los NNA vinculadas al Centro AMAR San Cristóbal II, se encontraban ubicadas en los estratos 1, 2 y 3 . En el momento de la entrevista se encontró un aumento de las familias pertenecientes a los estratos 1 y 3 y una disminución en el estrato 2. Esto se explica, principalmente, por la restratificación realizada en la Secretaría de Planeación de Bogotá en el año 2009 (SDP, 2009), en la localidad de San Cristóbal. En términos de calidad de vida, entonces, el cambio de estrato no representa mejoras en sus condiciones, por lo contrario lleva a las familias a tener mayores egresos por rubros como el pago de servicios públicos.

Igualmente, se encontró un aumento en el número de familias que contaban con un salario mínimo, en el momento de ingreso y que incrementaron sus entradas de dinero, al pasar de 48,4\% (15 familias) a $64,5 \%$ (20 familias). Lo contrario ocurrió con las familias de ingresos mayores a un SMLV, las cuales disminuyeron 9,7 puntos porcentuales (3 familias menos), esto se observa en la gráfica 2 . Aunque dos estratos socioeconómicos aumentan su nivel de ingresos, hay que resaltar que la ciudad presenta problemas de desempleo, y el empleo que poseen los entrevistados no garantiza una mejor calidad de vida. De esto dan cuenta los hallazgos al visibilizar que la mayoría de las familias de los NNA desarrollaban actividades propias del empleo informal (ventas ambulantes y empleos esporádicos), en las cuales los NNA estaban involucrados.

Con respecto a la tenencia de vivienda, se observa en la gráfica 3, un aumento de 3,2\% en el número de familias ( 20 familias $64,5 \%$ y 21 familias $67,7 \%)$ que vivían en condiciones de arriendo o subarriendo (FAS), debido a la dificultad a la hora de adquirir un crédito para vivienda, pues dentro de las políticas de las entidades financieras está el de recibir un salario fijo, requisito que no cumplen estas familias. Sin embargo, en el momento post 5 familias cuentan con vivienda propia (FVP); es decir, el $16,1 \%$, gracias a que estas lograron ingresar a fondos de ahorro para adquirir casa propia.

Las familias en el momento de la entrevista tenían acceso a la mayoría de los servicios 
Gráfica 1 .

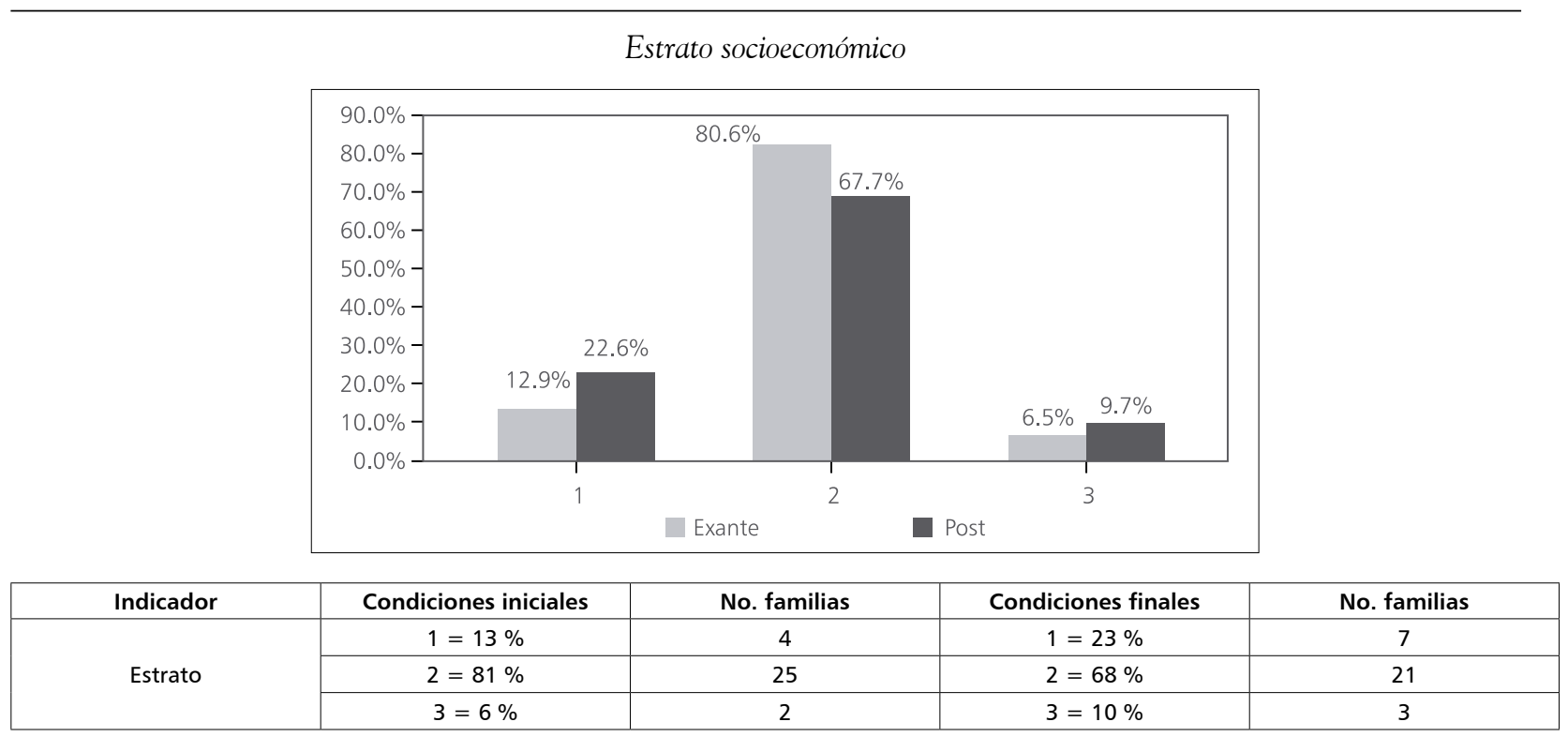

Fuente: Cálculos de las autoras.

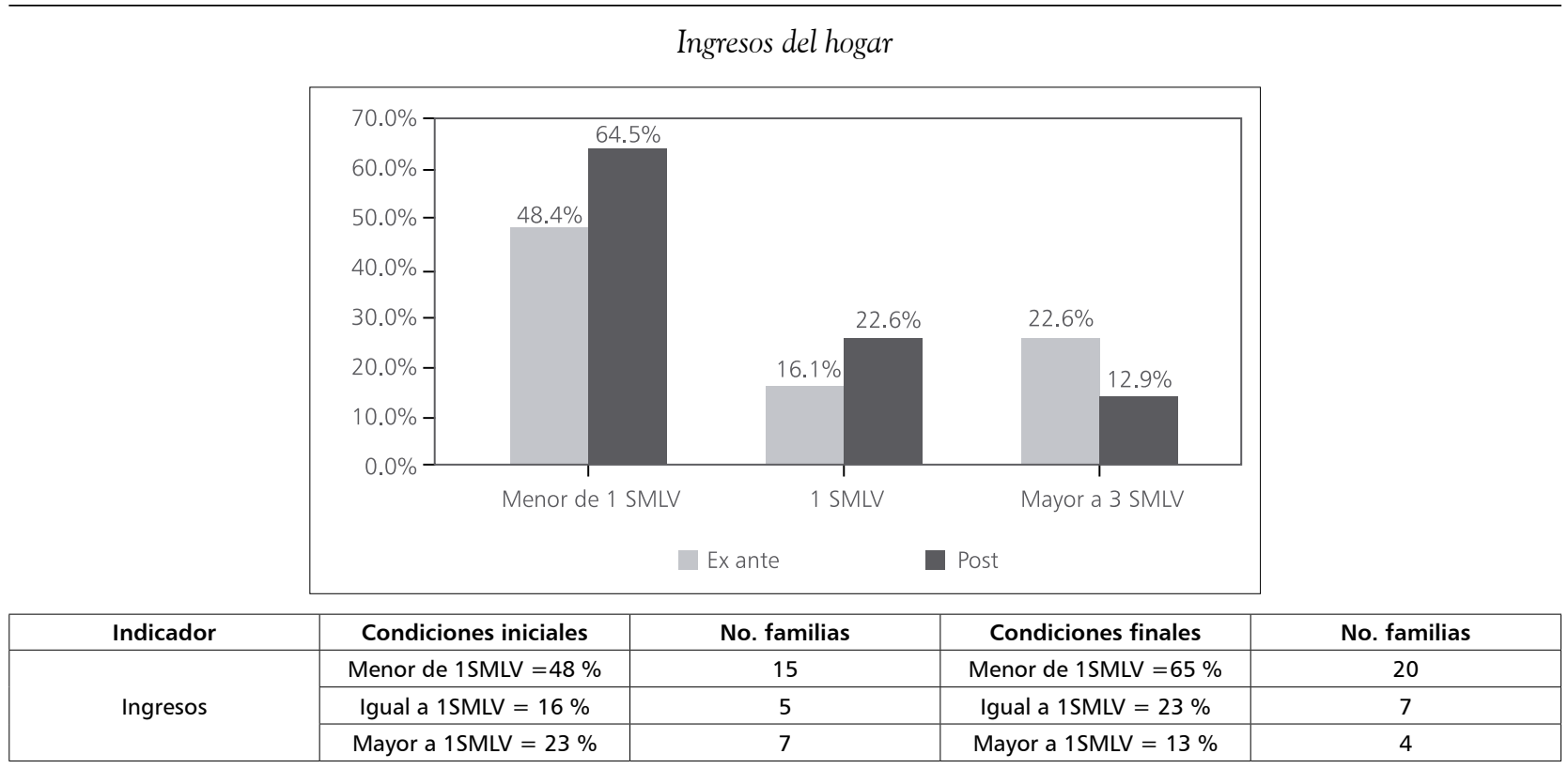

Fuente: Cálculos de las autoras.

públicos domiciliarios, como lo indica la tabla 2: 30 familias contaban con el servicio de energía eléctrica (FSEE), acueducto y alcantarillado (FSA). Por su parte, el gas natural fue el servicio público que aumentó significativamente su cobertura, al pasar de 13 a 22 familias.
Es importante que las familias cuenten con el acceso a todos los servicios públicos domiciliarios, puesto que estas condiciones son esenciales para llevar una vida digna y con calidad. Además, la prestación de servicios como el agua potable y la energía eléctrica son básicos para garantizar una adecuada salud. 
Tenencia de la vivienda

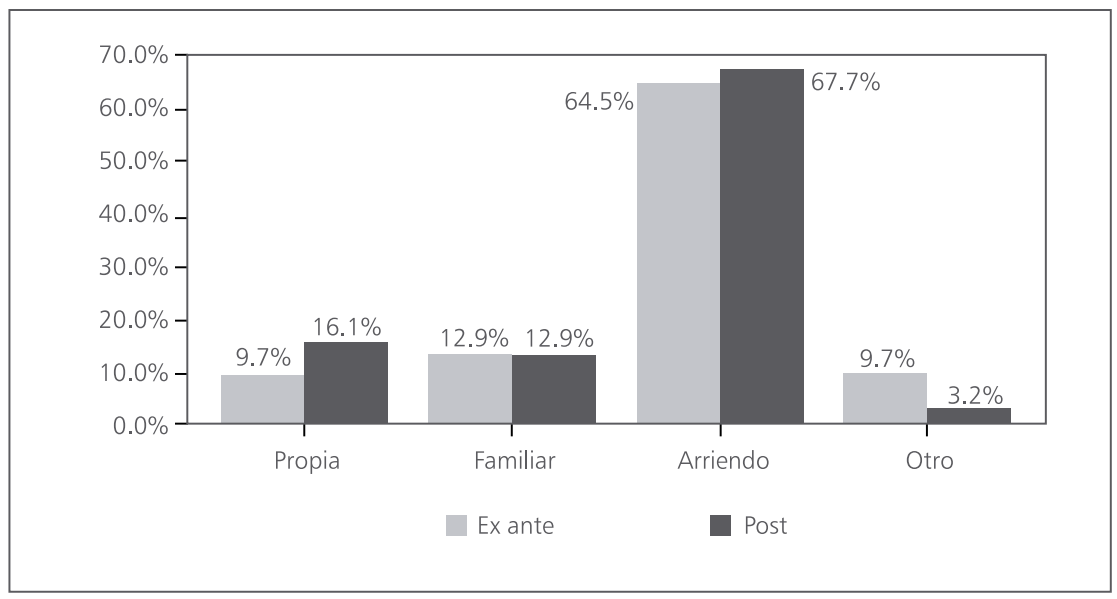

Fuente: Cálculos de las autoras.

En general, las condiciones de las familias en esta categoría no presentaron cambios significativos. Se hace necesario, entonces, desarrollar políticas públicas que de manera integral permitan a las familias mejorar su calidad de vida.

\section{Salud y nutrición}

En esta categoría se analizaron aspectos como la vinculación a un régimen de salud, peso de los NNA, tipo y frecuencia en el consumo de los alimentos que hacen parte de una dieta balanceada. Debido a que una de las prioridades del programa Centro
AMAR es que todos sus beneficiarios se encuentren vinculados a algún régimen de salud, el régimen subsidiado presentó un aumento significativo en el número de afiliaciones al pasar del 51,8\% (29 NNA) al 78,6\% (44 NNA). En el momento post, solo el $12,5 \%$ (correspondiente a 7 NNA) se encontraba afiliado al régimen contributivo, debido a que la mayoría de los empleos de los familiares eran temporales, circunstancia que propicia bajos ingresos $y$, por consiguiente, impide la afiliación a este régimen. Además, se encontró que el 1,8\% (1 NNA) del total de los entrevistados estaba afiliado(a) al sistema de salud por medio del régimen vinculado (gráfica 4).

Tabla 2.

Servicios públicos domiciliarios

\begin{tabular}{|c|c|c|c|c|}
\hline Indicador $^{4}$ & Condiciones iniciales & No. familias & Condiciones finales & No. familias \\
\hline FSEE & $87,1 \%$ & 28 & $96,8 \%$ & 30 \\
\hline FSGN & $41,9 \%$ & 13 & $71,0 \%$ & 22 \\
\hline FSA & $87,1 \%$ & 27 & $96,8 \%$ & 30 \\
\hline FSRB & $83,9 \%$ & 26 & $71,0 \%$ & 22 \\
\hline FSAP & $83,9 \%$ & 26 & $67,7 \%$ & 21 \\
\hline
\end{tabular}

Fuente: Cálculos de las autoras.

4 FSEE: familias con servicio de energía eléctrica.

FSGN: familias con servicio de gas natural.

FSA: familias con servicio de acueducto.

FSRB: familias con servicio de recolección de basuras.

FSAP: familias con servicio de alumbrado público. 
El número de afiliaciones de los NNA se incrementó, en parte por la implementación de la política pública del Gobierno nacional, que busca que la totalidad de la población se encuentre vinculada a alguno de los regímenes de salud. Sin embargo, al momento de calificar la prestación del servicio, se identificaron dificultades relacionadas con moras en la asignación de citas médicas e ineficiencia en el cubrimiento de los medicamentos más costosos. En términos de calidad de vida, y de acuerdo a las capacidades básicas listadas por Nussbaum (2007), la afiliación al sistema de salud es un factor trascendental para el logro de una vida digna, por lo que el Estado tiene la responsabilidad de garantizarla.

Al ingreso al programa se establece la condición nutricional de los 56 NNA, como se observa en la tabla 3. La mayor parte de los NNA $(66,1 \%)$ se encontraban en condiciones nutricionales normales, el 3,6\% se encontraban bajos de peso, el $10,7 \%$ tenía sobrepeso y el 3,6\% estaban en nivel crónico; es decir, en situación de desnutrición.

Los hábitos alimenticios de los NNA durante la permanencia en el Centro AMAR San Cristóbal II cambiaron. Se identificó que el 96,4\% correspon- diente a 54 NNA mejoraron su dieta. Sin embargo, para el 3,6\% (2 NNA), las dificultades económicas no permitieron obtener un nivel adecuado de nutrición.

Respecto a la frecuencia de consumo de los alimentos como la carne, los vegetales, los cereales y las frutas necesarios y que aportan los nutrientes que los NNA necesitan, en la tabla 4 se observa un adecuado consumo de estos. El alcance de estos resultados, posiblemente, se debió al acompañamiento nutricional brindado desde Centro AMAR, programa por medio del cual se fomentó la práctica de una dieta balanceada y el consumo de alimentos según las necesidades particulares de NNA en cuanto al crecimiento y desarrollo físico y mental.

\section{Educación}

La tasa de asistencia escolar (TAE), en comparación con la situación inicial, presentó un incremento de 14,2 puntos porcentuales, alcanzado por el apoyo brindado desde las áreas de pedagogía y psicología del Centro AMAR (gráfica 5), así en el momento post el $94,6 \%$ de los 56 NNA asistía a una institución educativa.

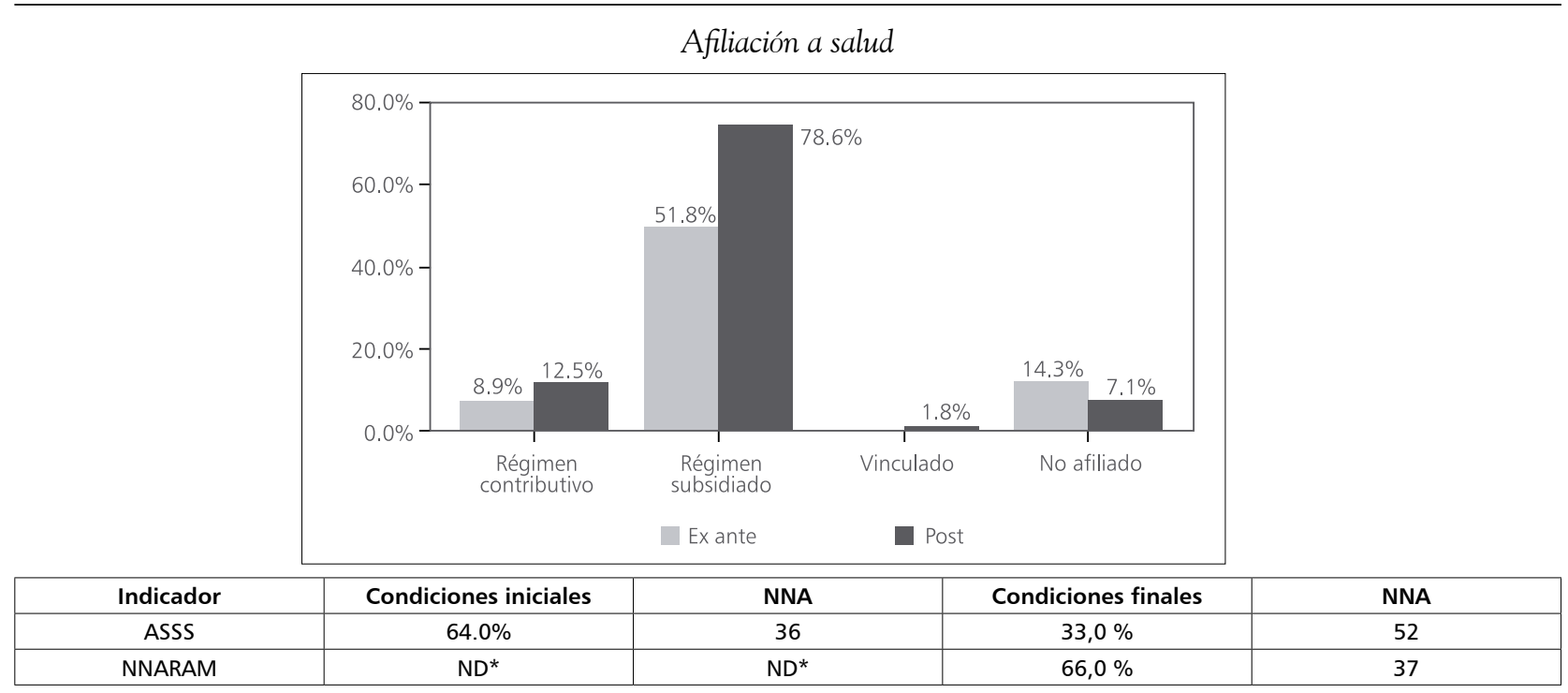

Fuente: Cálculos de las autoras.

*No disponible.

ASSS: Afiliado al sistema de seguridad social. NNARAM: NNA que recibieron atención médica. 
ANÁLISIS DE LAS CONDICIONES DE VIDA DE LOS BENEFICIARIOS DEL PROGRAMA CENTRO AMAR DE LA LOCALIDAD DE SAN CRISTÓBAL EN BOGOTÁ, COLOMBIA

Tabla 3.

Diagnóstico nutricional inicial

\begin{tabular}{|c|c|c|c|c|}
\hline Peso & Normal & Bajo peso & Sobrepeso & Crónico \\
\hline NNA & 37 & 2 & 6 & 2 \\
\hline Porcentaje & $66,1 \%$ & $3,6 \%$ & $10,7 \%$ & $3,6 \%$ \\
\hline
\end{tabular}

Fuente: Cálculos de las autoras.

Tabla 4.

Frecuencia de consumo de alimentos

\begin{tabular}{|c|c|c|c|c|c|c|}
\hline Frecuencia Alimentos & Siempre & NNA & A veces & NNA & Nunca & 0 \\
\hline Carne & $51,8 \%$ & 29 & $48,2 \%$ & 27 & 14 & $12,5 \%$ \\
\hline Vegetales & $62,5 \%$ & 35 & $25 \%$ & 15 & $7,1 \%$ \\
\hline Cereales & $66,1 \%$ & 37 & $26,8 \%$ & 4 & 15 & \\
\hline Frutas & $58,9 \%$ & 33 & $26,8 \%$ & 8 & $14,3 \%$ \\
\hline
\end{tabular}

Fuente: Cálculos de las autoras.

Por otra parte, la tasa de no asistencia escolar (TNAE) muestra que la deserción educativa presentó una disminución de 7 puntos básicos; de los 56 NNA entrevistados solo el 3,6\% (2 NNA) estaban desescolarizados en el momento de la entrevista. Esto se debe a factores como el desinterés en el aprendizaje y el mayor beneficio que le reporta el trabajo, representado en la posibilidad de poder adquirir bienes adicionales a los otorgados por sus familiares (gráfica 5).
La tabla 5 muestra que, en el momento post, la ayuda que brindaban los cuidadores de NNA en el desarrollo de actividades académicas era baja, ya que tan solo el $21,4 \%$ de estas personas (correspondiente a 12 NNA) siempre estaba dispuesto a brindar apoyo en la realización de tareas y demás aspectos que demanda el desarrollo del proceso educativo. El 51,8\% (correspondiente a 29 NNA) los orientaba tan solo en algunas ocasiones y el $17,9 \%$ (correspondiente a 10 NNA) nunca estaba

Gráfica 5 .

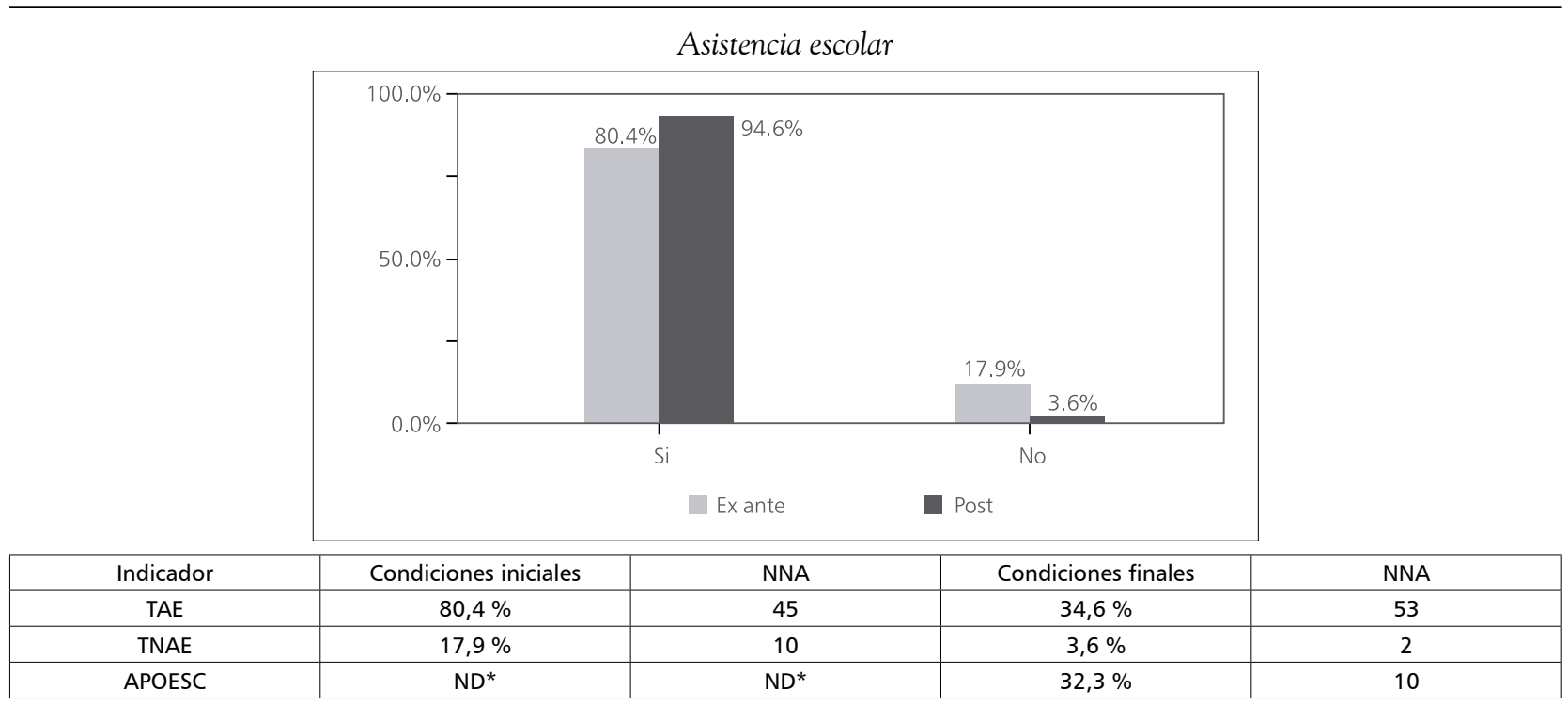

Fuente: Cálculos de las autoras.

* No disponible

TAE: Tasa de asistencia escolar. TNAE: Tasa de no asistencia escolar. APOESC: Apoyo escolar 
Tabla 5.

APOESC: Apoyo escolar

\begin{tabular}{|c|c|c|c|}
\hline Escala & Criterio de calificación & NNA & Porcentaje \\
\hline 0 & Nunca & 10 & $17,9 \%$ \\
\hline $33,33 \%$ & Pocas veces & 29 & $51,8 \%$ \\
\hline $66,66 \%$ & Casi siempre & 5 & $8,9 \%$ \\
\hline $100 \%$ & Siempre & 12 & $21,4 \%$ \\
\hline
\end{tabular}

Fuente: Cálculos de las autoras.

pendiente de que los NNA cumplieran con el desarrollo óptimo de sus responsabilidades académicas.

Para el indicador apoyo escolar (APOESC) se observa que, en el momento post, 29 NNA eran apoyados en la realización de actividades escolares pocas veces $(33,33 \%)$ por sus acudientes; 12 NNA siempre $(100 \%)$ recibían un apoyo escolar por parte de sus familiares.

El $96,4 \%$ de las personas entrevistadas considera la educación como medio de desarrollo y progreso (EDUD) para los NNA, en la medida en que esta les garantiza una estabilidad laboral con un nivel de salario suficiente para suplir sus necesidades básicas; asimismo, minimiza las brechas de pobreza, a las que se ve sujeta esta población.
Con respecto al nivel de escolaridad (gráfica 6), el 57,1\% de NNA se encontraba en básica secundaria, en comparación con un $37,5 \%$ en el momento de vinculación al programa. Cabe resaltar que los respectivos niveles responden a las edades en las que se hallaba la población, puesto que al ingreso las edades oscilaban entre los 6 y los 11 años y al momento de la entrevista estaban en la adolescencia. También se identificó que el 1,8\% de los NNA se encontraba en el nivel técnico.

El Ministerio de Educación Nacional (2003) ha establecido cinco categorías de rango de edad, según el nivel educativo que debe estar cursando el NNA: 1) transición, cuya edad específica es de 5 años; 2 ) básica primaria, con edades que oscilan

Nivel de escolaridad

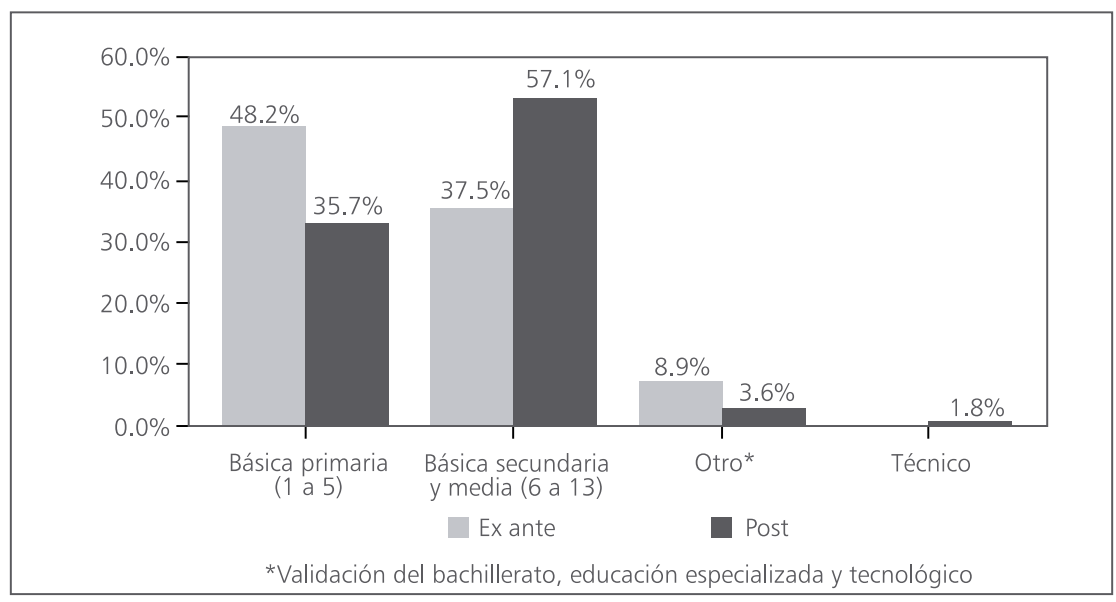

Fuente: Cálculos de las autoras. 
entre los 6 y los 10 años; 3) básica secundaria, que corresponde a las edades de 11 a 14 años; 4) media, de 15 a 16 años, y 5) la educación superior, cuyo rango de edad va de 17 a 21 años.

Con base en estos rangos, se calcula el indicador asistencia escolar según rango de edad (AERE), que se muestran en la tabla 6, el cual no presenta datos iniciales debido a la falta de información. Para el rango de edad de los 11 a 14 años, se evidenció una alta disparidad del nivel educativo, se resalta que el $24 \%$ de estos NNA no cumplen con las condiciones requeridas, ya que en el momento post cursaban preescolar (4\%) y primaria (20\%). Y para la edad de 17 a 21 años, estos NNA debían encontrarse realizando alguna carrera profesional o vinculados en un programa técnico o tecnológico; sin embargo, se encontró que el $71 \%$ de los NNA cursaban básica secundaria.

Es importante resaltar que la culminación de los años escolares por fuera del rango de edad establecido hace que las oportunidades que se tienen para ingresar a una empresa se vayan reduciendo en la medida en que a las compañías les interesa recibir personas jóvenes altamente calificadas con un buen nivel educativo.

De igual manera, la calidad de vida, la asistencia escolar y el apoyo que le brinden los familiares a NNA en la realización de las actividades académicas resultan indispensables para el desarrollo de sus capacidades y competencias. Los resultados muestran una vinculación a las actividades educativas por parte de los NNA. Sin embargo, aún hace falta más apoyo por parte de los padres para el adecuado cumplimiento de sus labores académicas.

\section{Integridad física}

En esta categoría se abordaron las variables relacionadas con el objetivo principal del programa Centro AMAR; esto es, la disminución del trabajo infantil. Además, se tuvieron en cuenta aspectos relacionados con el maltrato a los NNA. La tabla 7 muestra que la tasa de trabajo infantil en los NNA disminuyó en 26,8 puntos porcentuales al pasar de 39,3\% (22 NNA) a 12,5\% (7 NNA). Esta disminución de la participación de los menores en el mercado laboral se presentó debido probablemente a las capacitaciones realizadas desde el programa, a la prioridad que se le dio al NNA para su desarrollo y libre formación, y al hecho que ya los NNA no ejercían el trabajo de forma permanente, sino eventual.

Asimismo, como se puede observar en la tabla 7, el porcentaje de NNA que eran empleados por familiares (NNAEF) al inicio de la vinculación al programa Centro AMAR era de $86,4 \%$ y al momento de realizar la entrevista era de $14,3 \%$ y los NNA que eran empleados por personas externas al hogar (NNAEPE) disminuyó de $9,1 \%$ a 1,8\%.

Por otro lado, el 5,4\% (3 NNA) al momento de realizar la entrevista era independiente o trabajaba por su cuenta, debido a que cumplió la mayoría de edad y tiene la necesidad de dar

Tabla 6.

Asistencia escolar según rango de edad

\begin{tabular}{|c|c|c|c|c|c|c|c|c|c|c|c|c|c|}
\hline 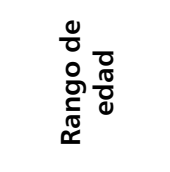 & 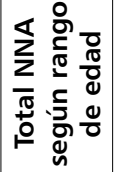 & 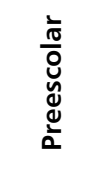 & $\sum_{z}^{\frac{\pi}{2}}$ & 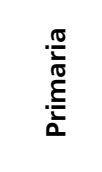 & $\sum_{z}^{\nwarrow}$ & 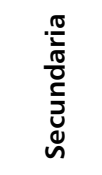 & $\sum_{z}^{\frac{1}{2}}$ & 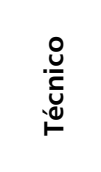 & $\sum_{z}^{\nwarrow}$ & 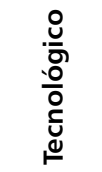 & $\sum_{z}^{\frac{\pi}{z}}$ & $\stackrel{0}{+⿱ 亠 䒑}$ & $\sum_{z}^{\nwarrow}$ \\
\hline $6-10$ años & 16 & $0,0 \%$ & 0 & $93,8 \%$ & 15 & $6,3 \%$ & 1 & $0,0 \%$ & 0 & $0,0 \%$ & 0 & $0,0 \%$ & 0 \\
\hline 11 - 14 años & 25 & $4,0 \%$ & 1 & $20,0 \%$ & 5 & $72,0 \%$ & 18 & $0,0 \%$ & 0 & $0,0 \%$ & 0 & $4,0 \%$ & 1 \\
\hline 15 - 16 años & 8 & $0,0 \%$ & 0 & $0,0 \%$ & 0 & $\begin{array}{c}100,0 \\
\%\end{array}$ & 8 & $0,0 \%$ & 0 & $0,0 \%$ & 0 & $0,0 \%$ & 0 \\
\hline 17 - 21 años & 7 & $0,0 \%$ & 0 & $0,0 \%$ & 0 & $71,4 \%$ & 5 & $14,3 \%$ & 1 & $14,3 \%$ & 1 & $0,0 \%$ & 0 \\
\hline
\end{tabular}

Fuente: Cálculos de las autoras. 
aportes económicos en los gastos de la familia.

El indicador TNNATRE (total de NNA que trabaja según rango de edad) presenta una disminución en el rango de 5 a 10 años del 100\%; en el rango de 15 a 21 años el porcentaje de NNA que trabaja se incrementó en un 9,1\% (2 NNA).

Las razones principales por las que inicialmente el NNA se encontró vinculado al mercado laboral fueron: el apoyo en la actividad económica familiar $(10,7 \%)$ y la formación en valores $(3,6 \%), y$, en el momento post, los motivos de mayor importancia se relacionaron con la preferencia por conseguir su propio dinero y evitar que el NNA se quedara solo en la casa, ambos con el 7,1\% (4 NNA).

En la gráfica 7 se observa que, del total de NNA, el 5,4\% (3 NNA) en el momento de realización de la entrevista utilizaba la calle como sitio de trabajo en comparación con el 51,8\% (29 NNA) que la usaba antes. También se presentó disminución del $100 \%$ en los trabajos realizados en establecimientos comerciales y lavado de autos. Finalmente, el acompañamiento en viviendas (servicio doméstico) se redujo al pasar de 19,6\% (11 NNA) a 8,9\% (5 NNA). Se considera que los talleres de formación orientados por los profesionales de las áreas de trabajo social y psicología de Centro AMAR San
Cristobal II contribuyeron a la reducción considerable de trabajo infantil de los NNA vinculados al programa durante los años 2007-2009. Esto permitió que los índices de escolaridad aumentaran y se fortaleciera el desarrollo de nuevas capacidades en el nivel educativo propuesto por Nussbaum (2007), para el mejoramiento en la calidad de vida de los NNA.

Uno de los problemas asociados que se identificó al inicio de la investigación fue el maltrato físico a los NNA. Desafortunadamente, esta problemática se agudizó al parecer por los patrones de crianza que los padres utilizan y que consideran como adecuados para el desarrollo de sus hijos. El indicador maltrato presentó un aumento de 18,75 puntos porcentuales aproximadamente. En el momento post, el castigo físico representaba el 57,1\% (32 NNA) y la agresión verbal el 48,2\% (27 NNA), contrario a ello, antes de la vinculación al programa, el maltrato en los NNA correspondía a 33,9\% (19 NNA).

Lo anterior evidencia la necesidad de ofrecer a los padres y a los cuidadores en general talleres en donde se les otorguen herramientas para la crianza de sus hijos y en donde se presenten alternativas para orientarlos en pro del desarrollo emocional y profesional de los NNA. En la medida en

Tabla 7.

Trabajo infantil en los NNA

\begin{tabular}{|c|c|c|c|c|}
\hline Indicador $^{5}$ & Condiciones iniciales & NNA & Condiciones finales & NNA \\
\hline \multirow{2}{*}{ TI } & $39,3 \%$ & 22 & $12,5 \%$ & 7 \\
\hline \multirow{2}{*}{ TNNATRE } & $5-10$ años $=40,9 \%$ & 9 & $5-10$ años $=0 \%$ & $11-14$ años $=28,6 \%$ \\
\cline { 2 - 5 } & $11-14$ años $=50,0 \%$ & 11 & $15-21$ años $=71,4 \%$ & 5 \\
\hline NNAEF & $15-21$ años $=9,1 \%$ & 2 & $14,3 \%$ & 1 \\
\hline NNAEPE & $86,4 \%$ & 19 & $1,8 \%$ & 32 \\
\hline \multirow{2}{*}{ MALTRATO } & $9,1 \%$ & 19 & Castigo físico $=57,1 \%$ & 27 \\
\cline { 2 - 5 } & $33,9 \%$ & & Agresión verbal $=48,2 \%$ & 2 \\
\hline
\end{tabular}

Fuente: Cálculos de las autoras.

5 TI: Tasa de trabajo infantil.

TNNATRE: total de NNA que trabajan según rango de edad. NNAEF: NNA empleados por familiares.

NNAEPE: NNA empleados por personas externas. 
Sitio de trabajo o acompañamiento

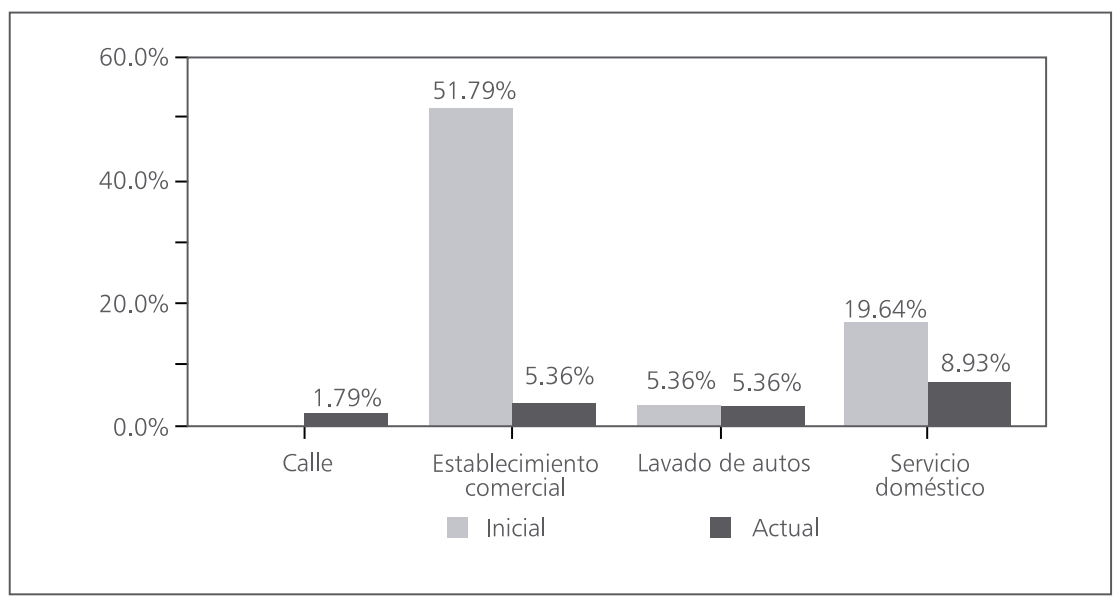

Fuente: Cálculos de las autoras.

que los ciudadanos son hombres de bien y contribuyen de una manera adecuada al fortalecimiento de una sociedad con un actuar en valores, las condiciones de un "buen vivir" y el desarrollo de las capacidades básicas para el mejoramiento de la calidad de vida se potencializan.

\section{Recreación y tiempo libre}

Para la capacidad humana básica de juego y recreación, los resultados permitieron identificar que el tiempo que más se compartía en familia respondía a lapsos que iban de 3 a 4 horas y de 5 a 6 horas diarias, tiempo que se utilizaba para apoyar al NNA en la realización de actividades escolares y acompañamiento a estos mismos durante la presentación en los programas televisivos de interés familiar (tabla 8). También se encontró que el domingo era el día en que más se compartía en familia con actividades recreativas, como salir al parque, las visitas a familiares y la asistencia a la iglesia.

En este sentido, es importante aclarar que el desarrollo de pocas actividades en familia está relacionado, según las familias entrevistadas, con la escasa disponibilidad de recursos económicos y el costo de oportunidad que les representaba, puesto que el tiempo libre que tenían preferían utilizarlo en la realización de los oficios del hogar.

Tabla 8.

Recreación y tiempo libre en familia

\begin{tabular}{|c|c|c|c|c|}
\hline Indicador & Condiciones iniciales & NNA & Condiciones finales & NNA \\
\hline \multirow{5}{*}{ RF } & \multirow{5}{*}{$N D^{*}$} & \multirow{5}{*}{$N D^{*}$} & Menos de 1 hora $=12,9 \%$ & 4 \\
\hline & & & 1 a 2 horas $=16,1 \%$ & 5 \\
\hline & & & 3 a 4 horas $=25,8 \%$ & 8 \\
\hline & & & 5 a 6 horas $=25,8 \%$ & 8 \\
\hline & & & Más de 6 horas $=19,4 \%$ & 6 \\
\hline
\end{tabular}

*No disponible. RF: recreación en familia. Fuente: Cálculos de las autoras. 


\section{CONCLUSIONES}

El trabajo infantil está relacionado a diversas problemáticas. Como se observa en la matriz de síntesis, para el caso de la categoría familia y redes sociales se encontró que no se propiciaban ambientes familiares basados en la comunicación, al igual que la corresponsabilidad de los progenitores frente al cuidado de los NNA estaba limitada al costo de oportunidad de trabajo por ocio.

Por otra parte, en cuanto a salud y nutrición se evidenció un incremento significativo en la vinculación al sistema de seguridad social, en su mayoría al régimen subsidiado. Sin embargo,

Matriz de sintesis

\begin{tabular}{|c|c|c|}
\hline CATEGORÍAS & CONDICIONES INICIALES - EX ANTE & CONDICIONES FINALES - EX POST \\
\hline \multirow{6}{*}{$\begin{array}{l}\text { FAMILIA } \\
\text { Y REDES } \\
\text { SOCIALES }\end{array}$} & $\begin{array}{l}\text { *Vulneración por ausentismo de uno de los padres. } \\
\text { Condiciones de hacinamiento. }\end{array}$ & $\begin{array}{l}\text { * Presencia de factores de riesgos o situaciones de maltrato infantil } \\
\text { relacionadas con el consumo de alcohol del progenitor, dificultades } \\
\text { en la comunicación y en las pautas de crianza. }\end{array}$ \\
\hline & * Predominio de familia uniparental, numerosa. & $\begin{array}{c}\text { * Poca participación de los NNA sobre las decisiones que se van a } \\
\text { tomar en el seno de la familia. }\end{array}$ \\
\hline & $\begin{array}{l}\text { * Poco tiempo para participar en espacios diferentes } \\
\text { al trabajo y la escuela. }\end{array}$ & * No se evidencian mejoras en la calidad de vida de las familias. \\
\hline & * Ingresos mínimos inferiores a un SMLV. & * Aumento en el número de familias con ingresos menores a un SMLV. \\
\hline & * Inestabilidad laboral. & * Aumentó la cobertura de los servicios públicos domiciliarios. \\
\hline & * Poca proyección como profesionales. & *Abandono de los NNA por algunos progenitores. \\
\hline \multirow{3}{*}{$\begin{array}{l}\text { SALUD Y } \\
\text { NUTRICIÓN }\end{array}$} & * No existía cultura de chequeo médico preventivo. & $\begin{array}{l}\text { * Los comedores comunitarios se convirtieron en redes de apoyo, } \\
\text { junto con Centro AMAR para mejorar los hábitos nutricionales. }\end{array}$ \\
\hline & * Se mejoraron los hábitos de higiene y asepsia. & * Prevalece la vinculación al régimen subsidiado. \\
\hline & $\begin{array}{l}\text { *Alimentación baja en nutrientes por falta de recursos } \\
\text { económicos. }\end{array}$ & * Mejoraron los hábitos alimenticios. \\
\hline \multirow[b]{2}{*}{ EDUCACIÓN } & * Fortalecimiento de conceptos. & $\begin{array}{l}\text { * Vinculación de la mayor parte de los NNA } \\
\text { a una institución educativa. }\end{array}$ \\
\hline & * Mayor motivación por las tareas escolares. & * Disminución en la deserción escolar. \\
\hline \multirow{4}{*}{$\begin{array}{l}\text { INTEGRIDAD } \\
\text { FÍSICA }\end{array}$} & * Se delega la labor de protección a Centro AMAR. & * Desarrollo de nuevas capacidades. \\
\hline & * Presencia de trabajo informal. & * Se mantienen las situaciones de violencia. \\
\hline & * No hay protección laboral para los NNA. & * Presencia de trabajo infantil de manera eventual. \\
\hline & $\begin{array}{l}\text { *Violencia intrafamiliar por problemas asociados } \\
\text { como el alcoholismo. }\end{array}$ & $\begin{array}{l}\text { * Se mantienen factores de riesgo como: inseguridad; venta y el } \\
\text { consumo de SPA; problemas de convivencia entre vecinos(as); } \\
\text { pandillismo; conformación de grupos con ideas de autoagresión. }\end{array}$ \\
\hline \multirow{2}{*}{$\begin{array}{l}\text { RECREACIÓN Y } \\
\text { TIEMPO LIBRE }\end{array}$} & \multirow{2}{*}{$\begin{array}{l}\text { * Poco tiempo dedicado a la recreación por las largas } \\
\text { jornadas laborales de los acudientes. }\end{array}$} & $\begin{array}{l}\text { * Utilización de espacios inadecuados como las calles para el desarrollo } \\
\text { de actividades recreativas (juego). }\end{array}$ \\
\hline & & * Poca disponibilidad de tiempo y espacio. \\
\hline
\end{tabular}

Fuente: Elaboración de las autoras 
al momento de calificar la prestación de este servicio, las familias entrevistadas identificaron dificultades relacionadas con moras en la asignación de citas médicas e ineficiencia en el cubrimiento de los medicamentos y tratamientos más costosos.

En cuanto a la categoría educación, el 94,6\% de los NNA asistía a una institución educativa gracias al apoyo brindado desde las áreas de pedagogía, psicología y por la labor de Centro AMAR de vincular a los NNA desescolarizados a los colegios. También se evidenció un mayor compromiso por parte de los padres con la educación de sus hijos.

En relación con la integridad física se haIló que existe una alta presencia de factores de riesgo como la inseguridad, venta y consumo de SPA, pandillismo, problemas de convivencia entre vecinos y conformación de grupos con ideas de autoagresión, aspectos que constituyen riesgos latentes que perturban a los NNA en el goce satisfactorio de sus derechos $y$, por consiguiente, en su desarrollo integral.

Finalmente, para la categoría recreación y el tiempo libre, los resultados permitieron identificar que el tiempo que se compartía en familia era utilizado para apoyar las actividades escolares o en el acompañamiento durante la presentación de programas televisivos de interés familiar.

De acuerdo con lo anterior y a partir del trabajo interdisciplinario realizado se presentan las siguientes reflexiones críticas a la Secretaría Distrital de Integración Social y a los diferentes actores involucrados en la ejecución de la política pública:

- Se necesitan estrategias pensadas desde el proceso y orientadas a la transformación de los fenómenos complejos con el fin de garantizar una vida digna para los NNA y su familia, además de ayudar a reducir la pobreza y la exclusión social.
- Las políticas públicas sociales deben ser diseñadas para el largo plazo. Así, se puede pensar en una transformación social.

- La sociedad civil, la academia y el sector público, articuladas en la construcción, ejecución y seguimiento de la política pública, democratizarán el conocimiento y transformarán la realidad.

- Un sistema de información eficiente entre los actores se hace necesario para el seguimiento y evaluación a la política pública.

- Los programas encaminados al aprovechamiento de las oportunidades de los beneficiarios hará que sean menos asistencialistas.

- Se requiere generar e implementar proyectos productivos que mitiguen las dificultades económicas de las familias.

- Cuando se involucra a la familia del NNA en los programas, dándole herramientas a los padres para afrontar y transformar sus realidades, los cambios estructurales en los hábitos y creencias de los adultos se verán reflejados en el futuro de los NNA.

- Se deben ampliar las oportunidades educativas y laborales.

- Los programas complementarios para reducir los problemas asociados como el consumo de SPA y para guiar algunas maneras de compartir el tiempo en familia son indispensables.

- Es esencial estimular la participación ciudadana para el seguimiento de las políticas públicas.

- Finalmente, cuando se identifiquen programas que logren los objetivos propuestos a nivel local, estos deberían ser contextualizados y aplicados en otras comunidades. 


\section{REFERENCIAS}

1. Alcaldía Mayor de Bogotá. (1999). Resolución 225 de 1999. Recuperado de http://www. alcaldiabogota.gov.co/sisjur/normas/Norma1.jsp?i=1068

2. Alcaldía Mayor de Bogotá. (2004a). Política por la calidad de vida de los niños, niñas y adolescentes, Bogotá 2004-2008. Bogotá: Departamento Administrativo de Bienestar Social del Distrito. Recuperado de http://www.bogota.gov.co/portel/minisites/ninosyninas/politicainfancia.pdf

3. Alcaldía Mayor de Bogotá. (2004b). Trabajo infantil en la central de abastos de Bogotá, Corabastos, Bogotá 2004. Bogotá: OIT/ IPEC Sudamérica, Proyecto Prevención Erradicación del Trabajo Infantil en la Centrade Abastos - Corabastos de Bogotá. Recuperado de http://white. oit.org.pe/ipec/boletin/documentos/diagnostico_corabastos.pdf

4. Alcaldía Mayor de Bogotá. (2009). Bogotá positiva le mete un gol al trabajo infantil. Recuperado de http://portel.bogota.gov.co/portel/libreria/php/x_frame_detalle.php?id=41923

5. Carvajal, A. (2008). Elementos de investigación social aplicada. Santiago de Cali: Universidad del Valle.

6. Consultoría para los Derechos Humanos y el Desplazamiento (Codhes). (2009). Población desplazada en Colombia, estadística general. Recuperado de http://www.alcaldiabogota.gov.co/ sisjur/normas/Norma1.jsp?i=36928.

7. Congreso de la República. (2006). Ley 1098 de 2006: Código de Infancia y Adolescencia. Colombia.

8. Departamento Administrativo Nacional de Estadística (DANE). (2007). Encuesta de calidad de vida Bogotá 2007. Recuperado de http:/www.dane.gov.co/files/investigaciones/condiciones_vida/ecvb/ECVB_07.pdf

9. Departamento Administrativo Nacional de Estadística (DANE). (2012). Boletín de prensa. Encuesta nacional de trabajo infantil 2011. Recuperado de http://www.dane.gov.co/files/investigaciones/boletines/ech/jobinfantil/bol_trabinf_2011.pdf

10. Delgado, P. (2001). Aspectos conceptuales sobre los indicadores de calidad de vida. Recuperado de http://aprendeenlinea.udea.edu.co/revistas/index.php/ceo/article/view/6803/6233

11. Fundación Centro de Investigación y Promoción Comunitaria (Ciproc). (2009). Quiénes somos. Recuperado de http://fundacionciproc.blogspot.com/

12. González, J. (2008). Informe de desarrollo humano: Una apuesta por Colombia. Bogotá: PNUD. Recuperado de http://hdr.undp.org/en/reports/national/latinamericathecaribbean/colombia/ IDH_2008_Bogota.pdf

13. Ministerio de Protección Social. (2008). Estrategia nacional para prevenir y erradicar las peores formas de trabajo infantil y proteger al joven trabajador 2008-2015. Comité Interinstitucional Nacional para la erradicación del trabajo infantil y la protección del NNA trabajador, Secretaría Técnica. Recuperado de http://www.crin.org/docs/estrategia_ti_colombia.pdf

14. Moreno, S. (2009). En 15 "Centros Amar" se trabaja en la erradicación del trabajo infantil. Recuperado de http://www.samuelalcalde.com/index.php?option $=$ com_content\&view $=$ article\&id $=$ 3560\%3Aen-15-centros-amar-se-trabaja-en-la-erradicacion-del-trabajo-infantil\&Itemid=29.

15. Nussbaum, M. (2007). Las fronteras de la justicia, consideraciones sobre la exclusión. Barcelona: Ediciones Paidós Ibérica SA.

16. Nussbaum, M., \& Sen, A. (1996). La calidad de vida (Primera edición en español). México D.F.: Fondo de Cultura Económica. 
17. Pereira, G. (2006). Capacidades individuales y capacidades colectivas. Sistema, 195, 35-51. Recuperado de http://www.academia.edu/178904/Capacidades_individuales_y_capacidades_colectivas

18. Quiroga, B. (2006). Trabajo infantil en los niños y jóvenes beneficiarios del programa familias en acción: una evaluación de impacto. Recuperado de https://www.dnp.gov.co/Portals/0/archivos/ documentos/DEE/Archivos_Economia/310.pdf

19. Sen, A. (2000). Desarrollo y libertad. Bogotá: Planeta.

\section{ANEXO A.}

\section{INSTRUMENTO PARA LA ENTREVISTA SEMIESTRUCTURADA}

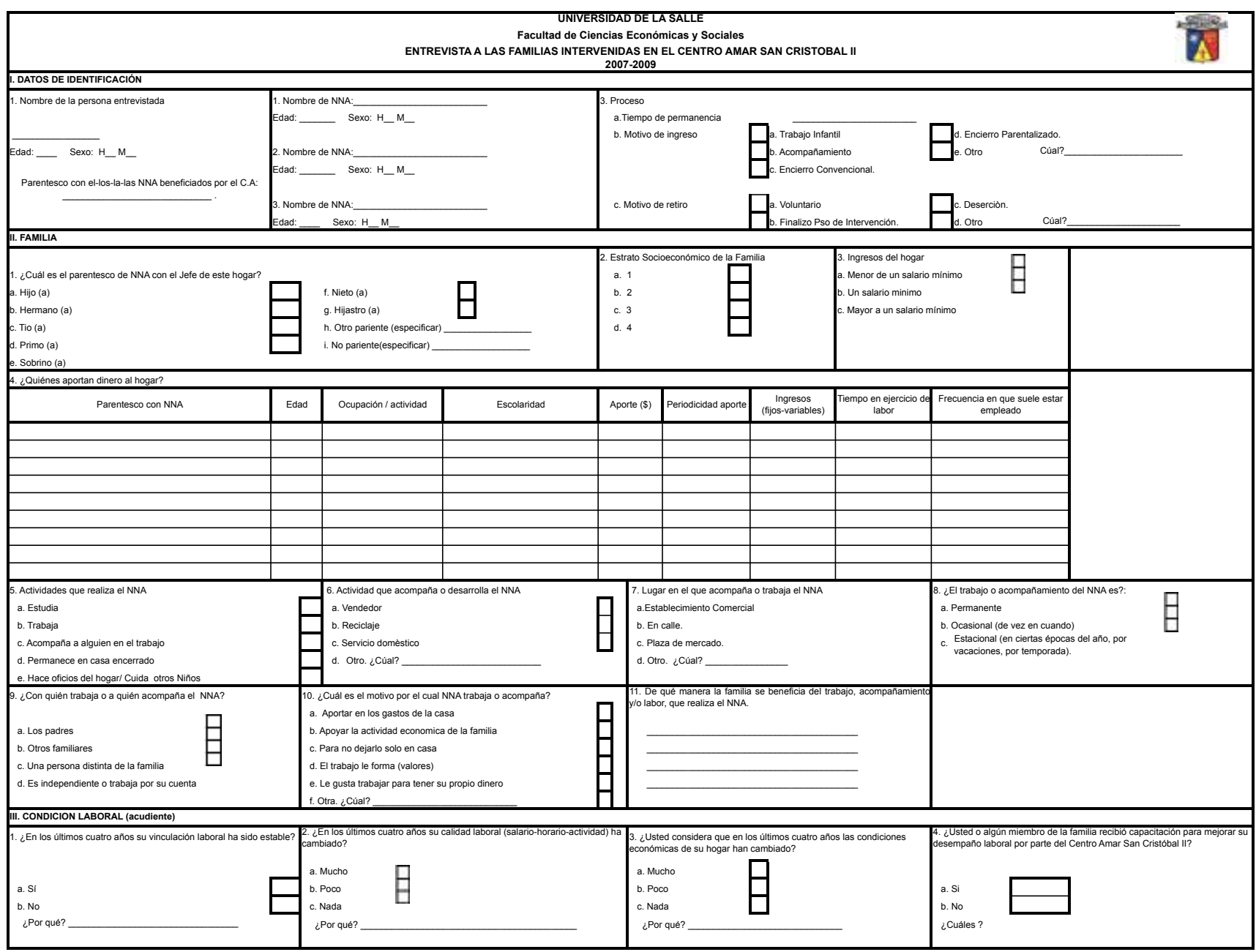




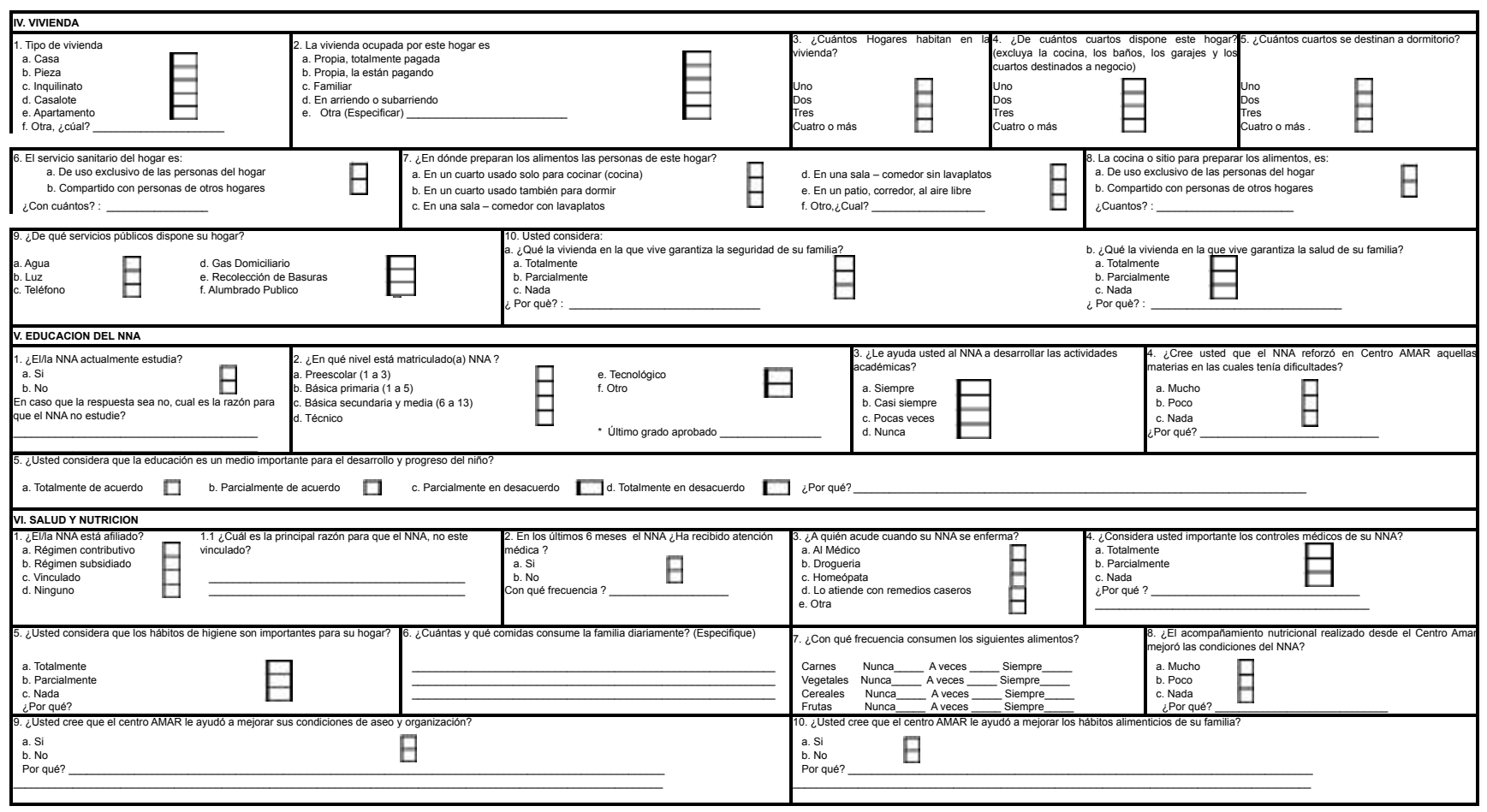

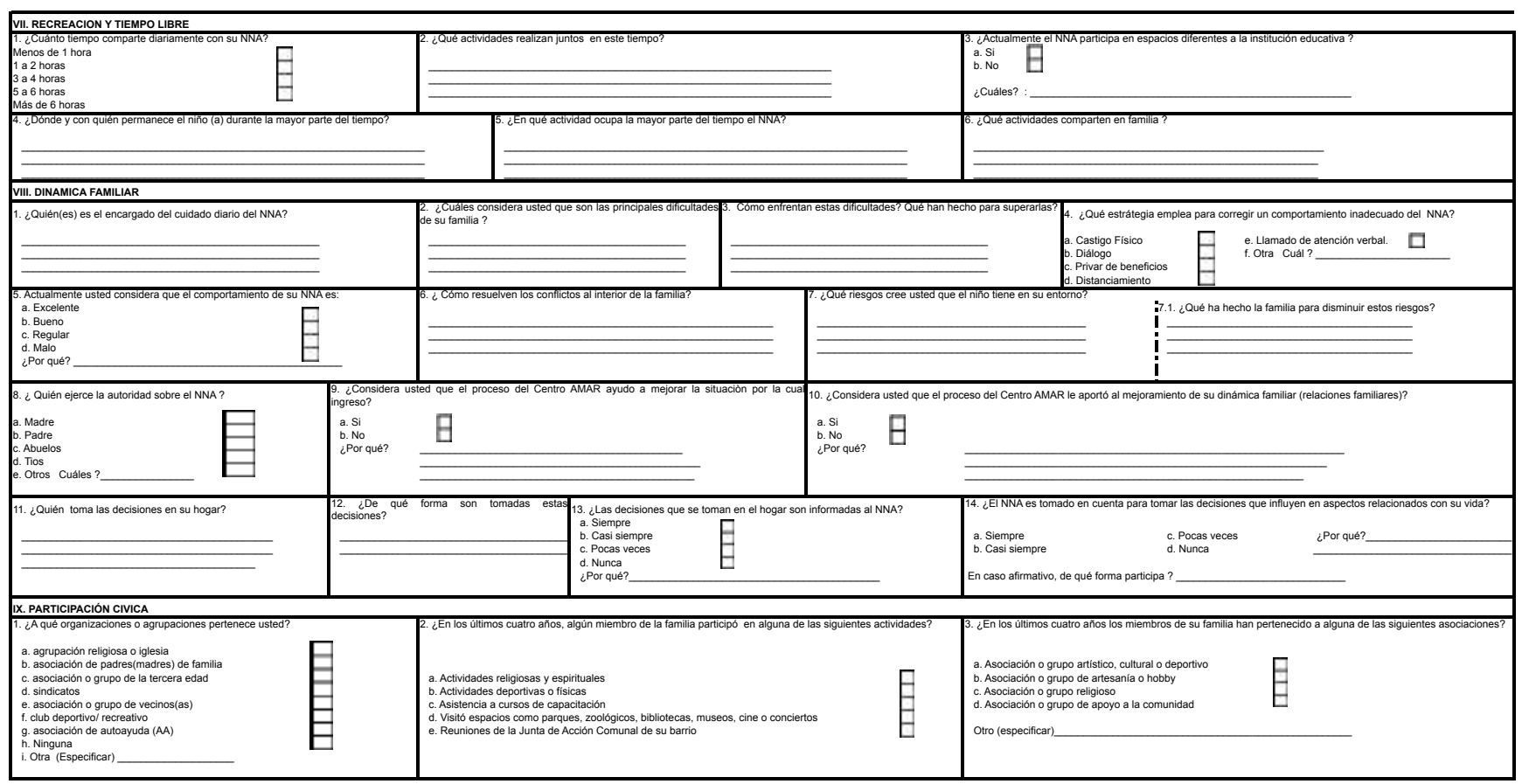


ANÁLISIS DE LAS CONDICIONES DE VIDA DE LOS BENEFICIARIOS DEL PROGRAMA CENTRO AMAR DE LA LOCALIDAD DE SAN CRISTÓBAL EN BOGOTÁ, COLOMBIA

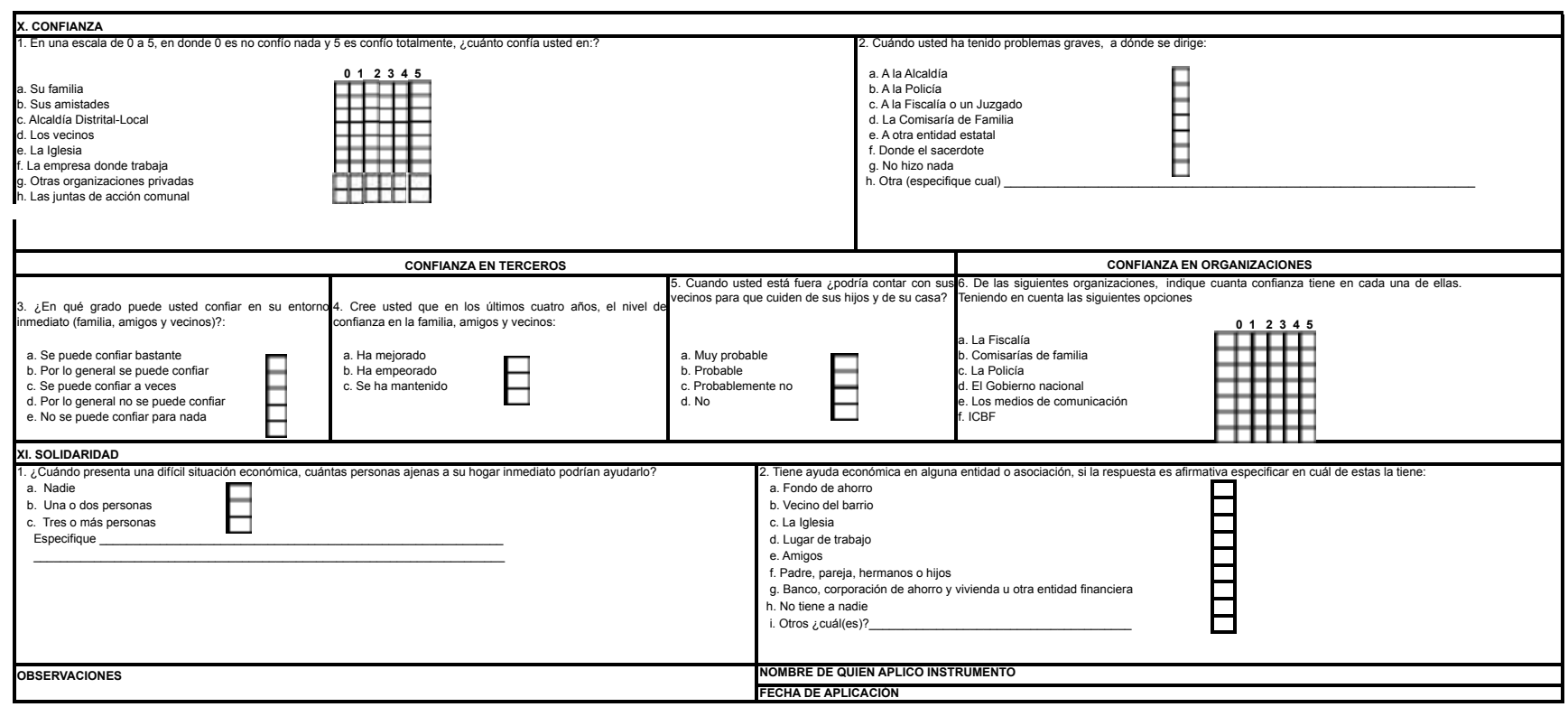

Fuente: Elaboración de las autoras 
ANEXO B.

INDICADORES

\begin{tabular}{|c|c|c|c|c|}
\hline 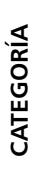 & 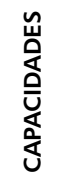 & 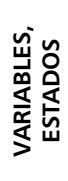 & 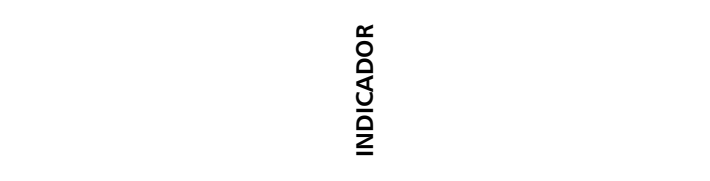 & $\frac{n}{\frac{n}{4}}$ \\
\hline \multirow{10}{*}{ 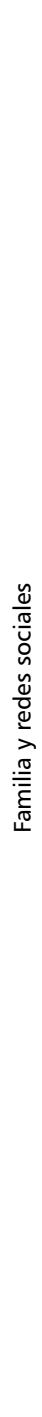 } & \multirow{9}{*}{ 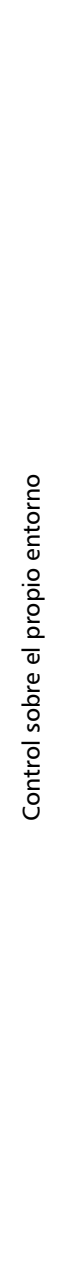 } & 㱏 & $\begin{array}{l}\text { ESTRATO: estrato socioeconómico } \\
\text { ESTRATO }=\frac{\text { Familias según estrato }}{\text { Total familias }} * 100\end{array}$ & $\begin{array}{l}\text { Determina el porcentaje de familias pertenece } \\
\text { a cada estrato socioeconómico. }\end{array}$ \\
\hline & & 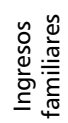 & $\begin{array}{c}\text { INGRESOS: } \text { nivel de ingresos en el hogar } \\
\text { ESTRATO }=\frac{\text { Familias según ingresos familiares }}{\text { Total familias }} * 100\end{array}$ & $\begin{array}{l}\text { Determina el porcentaje de familias que se } \\
\text { encuentra en cada nivel de ingreso. }\end{array}$ \\
\hline & & 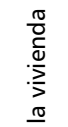 & $\begin{array}{l}\text { FVP: familias con vivienda propia } \\
F V P=\frac{\text { Familias con vivienda propia }}{\text { Total de familias }} * 100\end{array}$ & $\begin{array}{l}\text { Determina el porcentaje de familias que tienen } \\
\text { vivienda propia, pagada totalmente o que } \\
\text { están pagando. }\end{array}$ \\
\hline & & 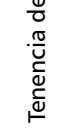 & $\begin{array}{l}\text { FAS: familias en arriendo o subarriendo } \\
F A S=\frac{\text { Familias en arriendo o subarriendo }}{\text { Total de familias }} * 100\end{array}$ & $\begin{array}{l}\text { Determina el porcentaje de familias que viven } \\
\text { en arriendo o subarriendo. }\end{array}$ \\
\hline & & \multirow{5}{*}{ 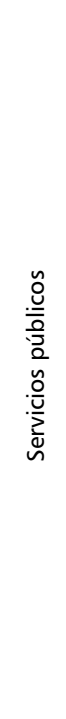 } & $\begin{array}{l}\text { FSEE: familias con servicio de energía eléctrica } \\
\text { FSEE }=\frac{\text { Familias con servicio de energía eléctrica }}{\text { Total de familias }} * 100\end{array}$ & $\begin{array}{l}\text { Determina el porcentaje de familias que } \\
\text { cuentan con el servicio de energía eléctrica. }\end{array}$ \\
\hline & & & $\begin{array}{l}\text { FSGN: familias con servicio de gas natural } \\
F S G N=\frac{\text { Familias con servicio de gas natural }}{\text { Total de familias }} * 100\end{array}$ & $\begin{array}{l}\text { Determina el porcentaje de familias que } \\
\text { cuentan con el servicio de gas natural. }\end{array}$ \\
\hline & & & $\begin{array}{c}\text { FSA: familias con servicio de acueducto } \\
\text { FSA }=\frac{\text { Familias con servicio de acueducto }}{\text { Total de familias }} * 100\end{array}$ & $\begin{array}{l}\text { Determina el porcentaje de familias que } \\
\text { cuentan con el servicio de acueducto. }\end{array}$ \\
\hline & & & $\begin{array}{c}\text { FSRB: familias con servicio de recolección de basura } \\
\text { FSRB }=\frac{\text { Familias con servicio de recolección de basuras }}{\text { Total de familias }} * 100\end{array}$ & $\begin{array}{l}\text { Determina el porcentaje de familias que cuentan } \\
\text { con el servicio de recolección de basura. }\end{array}$ \\
\hline & & & $\begin{array}{l}\text { FSAP: familias con servicio de alumbrado público } \\
\text { FSAP }=\frac{\text { Familias con servicio de alumbrado público }}{\text { Total de familias }} * 100\end{array}$ & $\begin{array}{l}\text { Determina el porcentaje de familias que } \\
\text { cuentan con el servicio de alumbrado público. }\end{array}$ \\
\hline & : & 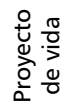 & $N A^{*}$ & $N A^{*}$ \\
\hline \multirow{3}{*}{ 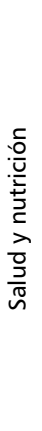 } & 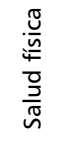 & $\frac{\frac{0}{2}}{\sqrt{0}}$ & $\begin{array}{c}\text { ASSS: afiliados al sistema de seguridad social en salud } \\
\text { ASSS }=\frac{\text { NNA afiliados al sistema de seguridad social en salud }}{\text { Total NNA }} * 100\end{array}$ & $\begin{array}{l}\text { Determina el porcentaje de NNA afiliados al } \\
\text { sistema de seguridad social en salud en calidad } \\
\text { de cotizantes o afiliados. }\end{array}$ \\
\hline & \multirow{2}{*}{ 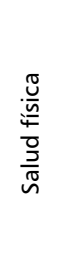 } & $\frac{\frac{0}{2}}{\sqrt[n]{n}}$ & $\begin{array}{l}\text { NNARAM: NNA que recibieron atención médica } \\
N N A R A M=\frac{\text { NNA que recibieron atención médica }}{\text { Total NNA }} * 100\end{array}$ & $\begin{array}{l}\text { Determina el porcentaje de NNA que recibieron } \\
\text { atención médica en los últimos seis meses. }\end{array}$ \\
\hline & & 恣 & $N A^{*}$ & $\begin{array}{l}\text { Frecuencia con la que se consumen diferentes } \\
\text { alimentos }\end{array}$ \\
\hline
\end{tabular}




\begin{tabular}{|c|c|c|c|c|}
\hline 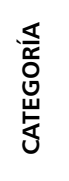 & 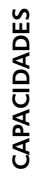 & 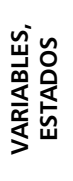 & $\begin{array}{l}\text { 高 } \\
\frac{0}{\zeta} \\
\frac{0}{2}\end{array}$ & $\frac{n}{\frac{M}{L}}$ \\
\hline \multirow{5}{*}{ 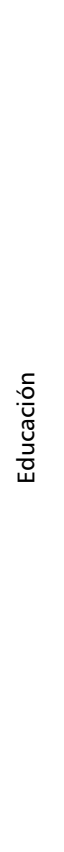 } & \multirow{5}{*}{ 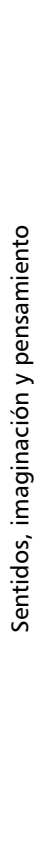 } & \multirow{5}{*}{ 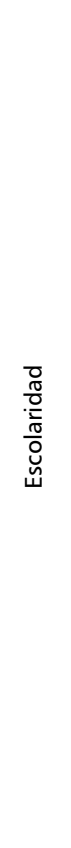 } & $\begin{aligned} \text { TAE: tasa de asistencia escolar } \\
\text { TAE }=\frac{\text { NNA que asiste a un plantel educativo }}{\text { Total NNA }} * 100\end{aligned}$ & $\begin{array}{l}\text { Determina la proporción de la población } \\
\text { que asiste a un centro de educación formal } \\
\text { (estudia). }\end{array}$ \\
\hline & & & $\begin{array}{c}\text { TNAE: tasa de no asistencia escolar } \\
\text { TAE }=\frac{\text { NNA que no asiste a un plantel educativo }}{\text { Total NNA }} * 100\end{array}$ & $\begin{array}{l}\text { Determina la proporción de los NNA que } \\
\text { no asiste a un centro de educación formal } \\
\text { (estudia). }\end{array}$ \\
\hline & & & $\begin{array}{c}\text { AERE: asistencia escolar según rango de edad } \\
\text { AERE }=\frac{\text { NNA que asiste a un plantel educativo según rango de edad }}{\text { Total NNA }} * 100\end{array}$ & $\begin{array}{l}\text { Determina la proporción de la población en un } \\
\text { rango de edad determinado que cursa el nivel } \\
\text { de escolaridad adecuado. }\end{array}$ \\
\hline & & & $\begin{array}{c}\text { APOESC: apoyo escolar } \\
\text { APOESC }=\frac{\text { NNA que reciben apoyo escolar según criterio }}{\text { Total NNA }} * 100\end{array}$ & $\begin{array}{l}\text { Determina la proporción de ayuda al NNA en } \\
\text { las actividades académicas }\end{array}$ \\
\hline & & & $\begin{array}{l}\text { EDUD: educación como medio de desarrollo y progreso } \\
\qquad E D U D=\frac{\text { Familias según rango seleccionado }}{\text { Total de familias }} * 100\end{array}$ & $\begin{array}{l}\text { Determina la proporción de familias que } \\
\text { consideran la educación como medio de } \\
\text { desarrollo y progreso. }\end{array}$ \\
\hline \multirow{5}{*}{ 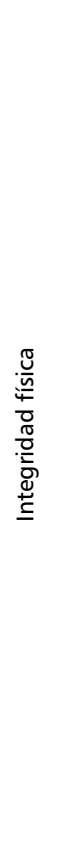 } & \multirow{5}{*}{ 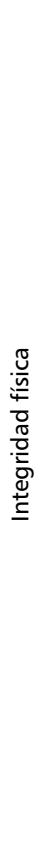 } & 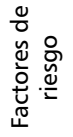 & $\begin{array}{c}\text { Maltrato: } \text { maltrato infantil } \\
\text { MALTRATO }=\frac{\text { NNA agredidos fisica o verbalmente }}{\text { Total de NNA }} * 100\end{array}$ & $\begin{array}{l}\text { Determina el porcentaje de NNA que padecen } \\
\text { algún tipo de agresión física o verbal. }\end{array}$ \\
\hline & & \multirow{4}{*}{ 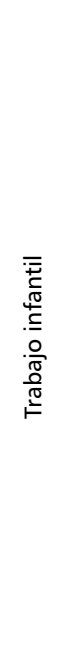 } & $\begin{array}{l}\text { TI: tasa de trabajo infantil } \\
T I=\frac{\text { NNA que trabajan }}{\text { Total de NNA }} * 100\end{array}$ & $\begin{array}{l}\text { Determina el porcentaje entre el número de } \\
\text { NNA que trabajan frente al total de NNA. }\end{array}$ \\
\hline & & & $\begin{array}{l}\text { TNNATRE: total de NNA que trabajan según rango de edad } \\
T N N A T R E=\frac{\text { NNA que trabajan según rango de edad }}{\text { Total de NNA }} * 100\end{array}$ & $\begin{array}{l}\text { Determina el porcentaje de NNA que se } \\
\text { encuentran trabajando de acuerdo a un rango } \\
\text { de edad. }\end{array}$ \\
\hline & & & $\begin{array}{l}\text { NNAEF: NNA empleados por familiares } \\
N N A E F=\frac{\text { NNA empleados por familiares }}{\text { Total de NNA trabajadores }} * 100\end{array}$ & $\begin{array}{l}\text { Determina el porcentaje de NNA empleados por } \\
\text { sus padres u otro familiar con respecto al total } \\
\text { de NNA trabajadores. }\end{array}$ \\
\hline & & & $\begin{array}{l}\text { NNAEPE: NNA empleados por personas externas } \\
N N A E P E=\frac{\text { NNA empleados por no familiares }}{\text { Total de NNA trabajadores }} * 100\end{array}$ & $\begin{array}{l}\text { Determina el porcentaje de NNA empleados por } \\
\text { personas externas a la familia con respecto al } \\
\text { total de NNA trabajadores. }\end{array}$ \\
\hline 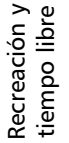 & 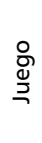 & 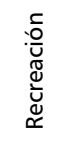 & $\begin{array}{c}\text { RF: recreación en familia } \\
R F=\frac{\text { Familias que comparten tiempo según rango de horas }}{\text { Total familias }} * 100\end{array}$ & $\begin{array}{l}\text { Determina el porcentaje de familias que } \\
\text { comparten tiempo en familia según un rango } \\
\text { de horas. }\end{array}$ \\
\hline
\end{tabular}




\section{ANEXO C.}

\section{CATEGORÍAS Y PREGUNTAS EN EL INSTRUMENTO}

\begin{tabular}{|c|c|c|c|}
\hline CATEGORÍA & $\begin{array}{l}\text { CAPACI- } \\
\text { DADES }\end{array}$ & $\begin{array}{l}\text { VARIABLES, } \\
\text { ESTADOS }\end{array}$ & PREGUNTAS \\
\hline \multirow{5}{*}{ 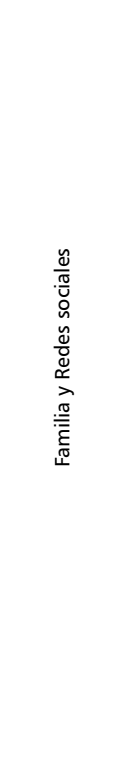 } & \multirow{4}{*}{ 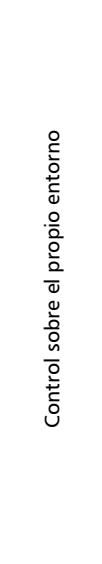 } & Estrato & II.2: Estrato socioeconómico de la familia. \\
\hline & & $\begin{array}{l}\text { Ingresos } \\
\text { familiares }\end{array}$ & $\begin{array}{l}\text { II.4: ¿Quiénes aportan dinero al hogar?, } \\
\text { III.1: ¿En los últimos cuatro años su vinculación laboral ha sido estable?, } \\
\text { III.2: ¿En los últimos cuatro años su calidad laboral (salario, horario, actividad) ha cambiado?, } \\
\text { III.3: ¿Usted considera que en los últimos cuatro años las condiciones económicas de su hogar han cambiado?, y } \\
\text { III.4: ¿Usted o algún miembro de la familia recibió capacitación para mejorar su desempeño laboral por parte del Centro AMAR } \\
\text { San Cristóbal II? }\end{array}$ \\
\hline & & $\begin{array}{c}\text { Tenencia de la } \\
\text { vivienda }\end{array}$ & $\begin{array}{l}\text { IV.2: La vivienda ocupada por este hogar es: propia, totalmente pagada; propia, la están pagando; familiar; en arriendo o } \\
\text { subarriendo; y otra. } \\
\text { IV.1: Tipo de vivienda. }\end{array}$ \\
\hline & & $\begin{array}{l}\text { Servicios } \\
\text { públicos }\end{array}$ & IV.9: ¿De qué servicios públicos dispone su hogar? \\
\hline & 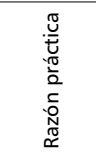 & $\begin{array}{l}\text { Proyecto de } \\
\text { vida }\end{array}$ & Transcripciones de la entrevista semiestructurada \\
\hline \multirow{2}{*}{ 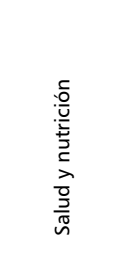 } & \multirow{2}{*}{ 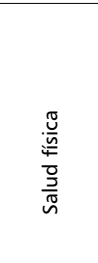 } & Salud & $\begin{array}{l}\text { VI.1: ¿El/la NNA está afiliado? y en caso de que el NNA no esté afiliado el análisis se complementa con las respuesta de la pregunta } \\
\text { VI.1.1: ¿Cuál es la principal razón para que el niño(a) no esté vinculado? } \\
\text { VI.2: En los últimos } 6 \text { meses ¿el NNA ha recibido atención médica?, } \\
\text { VI.3: ¿A quien acude cuando su NNA se enferma?, } \\
\text { VI.4: ¿Considera usted importante los controles médicos de su NNA? y } \\
\text { VI.5: ¿Usted considera que los hábitos de higiene son importantes para su hogar? }\end{array}$ \\
\hline & & Nutrición & Transcripciones de la entrevista semiestructurada \\
\hline 总 & 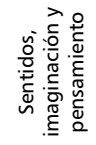 & Escolaridad & $\begin{array}{l}\text { V.1: ¿El/la NNA actualmente estudia? } \\
\text { V.2: ¿En qué nivel está matriculado(a) NNA y que grado cursa? } \\
\text { V.3: ¿Le ayuda usted al NNA a desarrollar las actividades académicas? } \\
\text { V.4: ¿Cree usted que el NNA reforzó en Centro AMAR aquellas materias en las cuales tenía dificultades? } \\
\text { V.5: ¿Usted considera que la educación es un medio importante para el desarrollo y progreso del niño? }\end{array}$ \\
\hline \multirow[b]{2}{*}{ 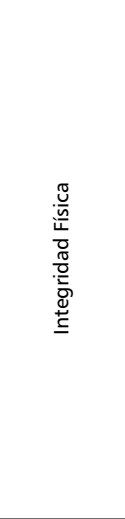 } & \multirow[b]{2}{*}{ 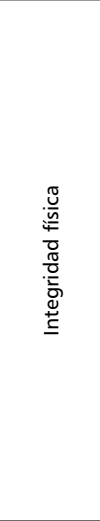 } & $\begin{array}{l}\text { Factores de } \\
\text { riesgo }\end{array}$ & $\begin{array}{l}\text { VIII.6: ¿Cómo resuelven los conflictos al interior de la familia? y VIII.4: ¿Qué estrategia emplea para corregir un comportamiento } \\
\text { inadecuado del NNA?; } \\
\text { VIII.5: Actualmente usted considera que el comportamiento de su NNA es: excelente, bueno, regular o malo, } \\
\text { VIII.1: ¿Quién(es) es el encargado del cuidado diario del NNA?, VIII.2: ¿Cuáles considera usted son las principales dificultades } \\
\text { de su familia?, } \\
\text { VIII.7: ¿Qué riesgos cree usted que el niño tiene en su entorno? y VIII.7.1: ¿Qué ha hecho la familia para disminuir estos riesgos? } \\
\text { y VIII.8: ¿Quién ejerce la autoridad sobre el NNA?, }\end{array}$ \\
\hline & & $\begin{array}{l}\text { Trabajo } \\
\text { infantil }\end{array}$ & $\begin{array}{l}\text { II.5: Actividad/es que realiza el/la NNA, } \\
\text { II.4: ¿Quiénes aportan dinero al hogar?, } \\
\text { II.6: Actividad que acompaña o desarrolla el NNA, } \\
\text { II.7: Lugar en el que acompaña o trabaja el NNA, } \\
\text { II.8: ¿El trabajo o acompañamiento del NNA es?, y } \\
\text { II.10: ¿Cuál es el motivo por el cual NNA trabaja o acompaña? } \\
\text { II.5: Actividad/es que realiza el/la NNA } \\
\text { II.9: ¿Con quién trabaja o a quién acompaña el NNA? y } \\
\text { II.11: De qué manera la familia se beneficia del trabajo, acompañamiento y/o labor, que realiza el NNA. } \\
\text { Infancia o edad preescolar: desde el nacimiento hasta los } 4 \text { años } \\
\text { Niñez: etapa cuando comienza la edad escolar desde los } 5 \text { hasta los } 10 \text { años } \\
\text { Pubertad: es el periodo durante el cual el NNA comienza su madurez sexual, de los } 11 \text { a los } 14 \text { años aproximadamente } \\
\text { Adolescencia: comienza a los } 15 \text { años hasta los } 21 \text { aproximadamente }\end{array}$ \\
\hline 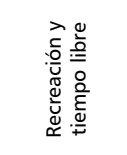 & 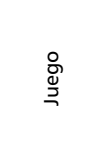 & Recreación & $\begin{array}{l}\text { VII.1: ¿Cuánto tiempo comparte diariamente con su NNA? } \\
\text { VII.2: ¿Qué actividades realizan en este tiempo? } \\
\text { VII.6: ¿Qué actividades comparten en familia? } \\
\text { VII.3: ¿Actualmente el NNA participa en espacios diferentes a la institución educativa?, } \\
\text { VII.4: ¿Dónde y con quién permanece el NNA durante la mayor parte del tiempo?, } \\
\text { VII.5: ¿En qué actividad ocupa la mayor parte del tiempo el NNA? }\end{array}$ \\
\hline
\end{tabular}

